\title{
A review of on-chip micro-evaporation: Experimental evaluation of liquid pumping and vapor compression driven cooling systems and control
}

\author{
Jackson Braz Marcinichen ${ }^{\mathrm{a}, *}$, Jonathan A. Olivier ${ }^{\mathrm{a}}$, Vinicius de Oliveira ${ }^{\mathrm{b}, 1}$, John R. Thome ${ }^{\mathrm{a}}$ \\ ${ }^{a}$ Laboratory of Heat and Mass Transfer (LTCM), École Polytechnique Fédérale de Lausanne (EPFL), Switzerland \\ ${ }^{\mathrm{b}}$ Automatic Control Laboratory (LA), École Polytechnique Fédérale de Lausanne (EPFL), Switzerland
}

\section{A R T I C L E I N F O}

\section{Article history:}

Received 2 August 2011

Received in revised form 13 October 2011

Accepted 14 October 2011

\section{Keywords:}

Data center

Microprocessor

On-chip two-phase cooling cycle

Micro-evaporator

Controller

\begin{abstract}
A B S T R A C T
Thermal designers of data centers and server manufacturers are showing a greater concern regarding the cooling of the new generation data centers, which consume considerably more electricity and dissipate much more waste heat, a situation that is creating a re-thinking about the most effective cooling systems for the future beyond conventional air cooling of the chips/servers. A potential significantly better solution is to make use of on-chip two-phase cooling, which, besides improving the cooling performance at the chip level, also adds the capability to reuse the waste heat in a convenient manner, since higher evaporating and condensing temperatures of the two-phase cooling system (from 60 to $95^{\circ} \mathrm{C}$ ) are possible with such a new "green" cooling technology. In the present project, two such two-phase cooling cycles using micro-evaporation technology were experimentally evaluated with specific attention being paid to (i) controllability of the two-phase cooling system, (ii) energy consumption and (iii) overall exergetic efficiency. The controllers were evaluated by tracking and disturbance rejection tests, which were shown to be efficient and effective. The average temperatures of the chips were maintained below the limit of $85^{\circ} \mathrm{C}$ for all tests evaluated in steady state and transient conditions. In general, simple SISO strategies were sufficient to attain the requirements of control. Regarding energy and exergy analyses, the experimental results showed that both systems can be thermodynamically improved since only about $10 \%$ of the exergy supplied is in fact recovered in the condenser in the present setup.
\end{abstract}

(c) 2011 Elsevier Ltd. All rights reserved.

\section{Contents}

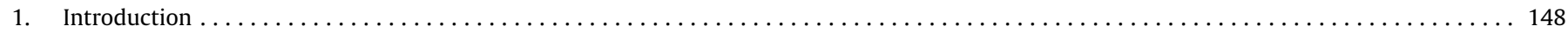

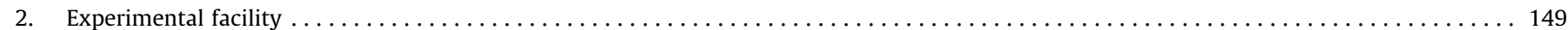

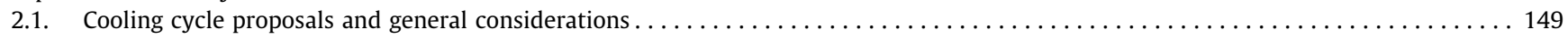

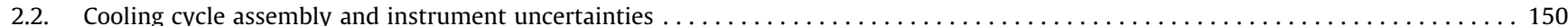

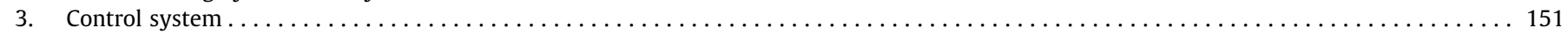

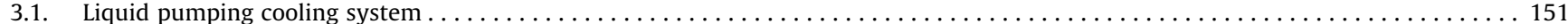

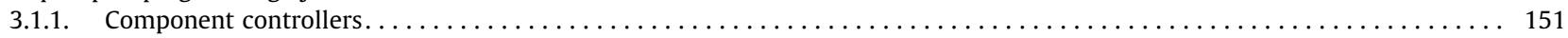

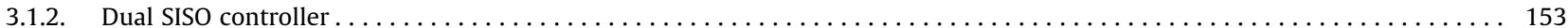

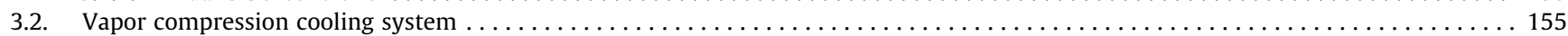

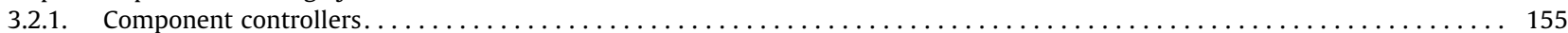

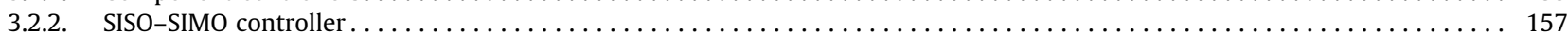

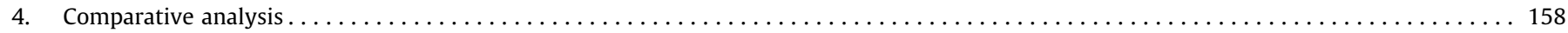

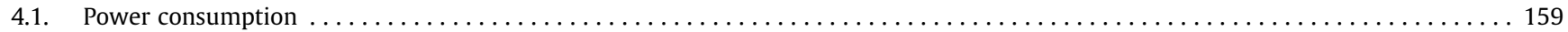

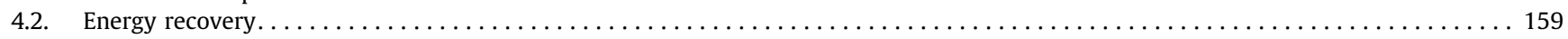

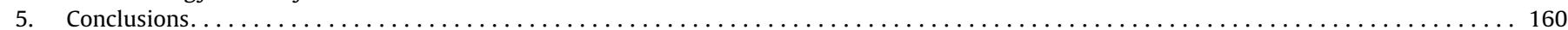

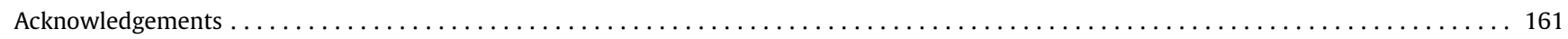

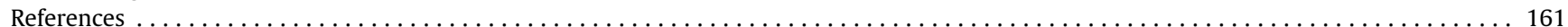

\footnotetext{
* Corresponding author. Tel.: +41 21693 5894; fax: +41 216935960 .

E-mail address: jackson.marcinichen@epfl.ch (J.B. Marcinichen).

1 Tel.: +4121693 3845; fax: +41216932574.
} 


\section{Nomenclature}

$\begin{array}{ll}\text { Roman } & \\ A_{S M V} & \text { stepper motor valve aperture, \% } \\ \dot{E}_{d} & \text { rate of exergy destruction due to irreversibilities within } \\ & \text { the control volume, W } \\ \dot{e}_{f i}, \dot{e}_{f e} & \text { inlet and outlet flow exergies, J/kg } \\ G & \text { transfer function of the system } \\ h_{i} & \text { ME inlet specific enthalpy, } \mathrm{JJ} / \mathrm{kg} \\ h_{o} & \text { ME outlet specific enthalpy, } \mathrm{kJ} / \mathrm{kg} \\ K_{C} & \text { PI proportional gain } \\ K_{I} & \text { PI integral gain } \\ K_{P} & \text { static gain of the system } \\ \dot{m} & \text { mass flow rate, kg/s } \\ \dot{m}_{i}, \dot{m}_{e} & \text { inlet and outlet mass flow rate, } \mathrm{kg} / \mathrm{s} \\ p & \text { position of the pole in the complex plan } \\ \mathrm{PC}_{\mathrm{C}} & \text { condensing pressure, bar } \\ \mathrm{Pc}_{s p} & \text { set point of condensing pressure, bar } \\ P_{i} & \text { ME inlet pressure, bar } \\ P_{o} & \text { ME outlet pressure, bar } \\ \dot{Q}_{j} & \text { heat transfer rate, W } \\ T_{i} & \text { ME inlet temperature, }{ }^{\circ} \mathrm{C} \\ T_{j} & \text { instantaneous temperature, }{ }^{\circ} \mathrm{C} \\ T_{I} & \text { integral time } \\ T_{0} & \text { dead state temperature, } \mathrm{K} \\ u & \text { system input } \\ \dot{W}_{c v} & \text { energy transfer rate by work, W } \\ \dot{W}_{i n p u t} & \text { pseudo chip input power, W } \\ x_{o} & \text { MEs' outlet vapor quality } \\ y & \text { system output } \\ z & \text { position of the zero in the complex plan } \\ & \end{array}$

Greek

$\Delta T_{c} \quad$ difference in temperature between outlet water flow and inlet working fluid flow in the condenser, ${ }^{\circ} \mathrm{C}$

$\theta \quad$ transport delay, $\mathrm{s}$

$\tau \quad$ time constant, $s$

$\tau_{D} \quad$ desired closed-loop time constant, s

Acronyms

CHF critical heat flux, $\mathrm{W} / \mathrm{cm}^{2}$

COP coefficient of performance

CPU central processing unit

EEV electric expansion valve

HE heat exchanger

HS heat spreader

iHEx internal heat exchanger

LP liquid pump

LPR low pressure receiver

LPS condenser liquid pump speed, rpm

ME micro-evaporator

MIMO multiple input multiple output

MMC multi-microchannel cooler

PCV pressure control valve

SMV stepper motor valve

SIMO single input multiple output

SISO single input single output

TCV temperature control valve

VC vapor compressor

\section{Introduction}

Under the current efficiency trends, the energy usage of data centers in the US is estimated to become more than 100 billion kWh by 2011, which represents an annual energy cost of approximately $\$ 7.4$ billion [1]. With the introduction of a proposed carbon tax in the US [2], the annual costs could become as high as $\$ 8.8$ billion by 2012, increasing annually. With the US having an annual increase of total electrical generation of approximately only $1.5 \%$ combined with the current growth rate of electrical energy by data centers being between $10 \%$ and $20 \%$ per annum (driven now even more by smart phones), data centers potentially will consume all of the electrical energy produced by 2030 if current growth rates continue! With air cooling of the servers in data centers accounting for most of the non-IT energy usage (up to 45\% [3] of the total energy consumption), this is the logical energy consumer that needs to be attacked to reduce its wasteful use.

Nowadays, the most widely used cooling strategy is refrigerated air cooling of the data centers' numerous servers. When making use of this solution, nevertheless, $40 \%$ or more of the refrigerated air flow typically by-passes the racks of servers in data centers all together, according to articles presented at ASHRAE Winter Annual Meeting at Dallas (January, 2007), while also "cooling" thousands of servers that are not even in operation. This massive waste of energy motivates the search for a new "green" cooling solution to the future generation of higher performance servers that consume much less energy for their cooling. One promising solution is the application of on-chip two-phase cooling to dissipate the high heat flux densities of server CPU's. The most promising working fluids for these applications appear to be conventional refrigerants, for instance HFC134a, as opposed to low pressure dielectric coolants (such as FC-72) or water-cooling.
Hannemann et al. [4] proposed a pumped liquid multiphase cooling system (PLMC) to cool microprocessors and microcontrollers of high-end devices such as computers, telecommunications switches, high-energy laser arrays and high-power radars. They emphasized the significant benefits of reduced pumping energy consumption, size and weight that were provided with the PLMC solution.

Mongia et al. [5] designed and built a small-scale refrigeration system applicable to a notebook computer, which included a minicompressor, a microchannel condenser, a microchannel evaporator and a capillary tube as the throttling device. COP's in the order of 3.7 were obtained, comparable with those obtained in modern household refrigerators.

Trutassanawin et al. [6] designed, built and evaluated the performance of a miniature-scale refrigeration system (MSRS) suitable for electronics cooling applications. It was concluded that although COP's in the order of 1.9-3.2 were obtained, a suitable control strategy was required to improve its performance.

Zhang et al. [7] developed a set of active control strategies to suppress the compressible flow boiling instabilities while also maintaining a reasonable electronic wall temperatures under transient heat load changes. They found that efficient and effective control was obtained by making use of only two actuators; a valve prior to the heated channel and a supply pump. However, no experimental evaluations of these systems were done to confirm their conclusions.

Zhou et al. [8] developed a steady-state model of a refrigeration system for high heat flux electronics cooling. The refrigeration system proposed consisted of multiple evaporators (microchannel technology), a liquid accumulator with an integrated heater, a variable speed compressor, a condenser and electric expansion valves (EEVs). Their main conclusions were: (i) the system COP could be improved without compromising the critical 
heat flux when handling higher heat fluxes, (ii) higher critical heat fluxes are achievable with a smaller EEV opening and higher heat input supplied to the accumulator and (iii) a trade-off between the system COP and CHF is necessary to prevent device burnout. Finally, they presented a preliminary validation of the model with initial experimental data showing a satisfactory prediction ability of the model.

Heydari [9] developed a simplified simulation program capable to design and evaluate performance of miniature refrigeration systems for high performance computers. The analysis of the system was based on a steady-state modeling of four components, i.e. compressor, condenser, evaporator and capillary tube. The two main points observed in the simulations were that firstly HFC134a is the most favorable refrigerant for CPU-cooling in combination with a vapor compression refrigeration system. Second, the condenser temperature has a much greater effect on the overall system efficiency than the evaporator temperature, with much higher COPs being observed at lower condensing temperatures.

Marcinichen and Thome [10], by means of a simulation code developed to evaluate electronic cooling cycles [11], performed thermo-hydrodynamic simulations of a vapor compression cycle and a liquid pumping cooling cycle using on-chip cooling with multi-microchannel evaporators. Water and different refrigerants were simulated. The results showed that for the liquid pumping cooling cycle, the pumping power consumption when using water was 5.5 times that obtained for two-phase HFC134a. These results can be considered the cooling system differential when compared with demonstration projects (excluding the energy consumption of the secondary fluid that removes the heat away from the rack), such as that for the new high performance computer called AQUASAR [12-14], which actually implemented a liquid water cooling cycle on an IBM rack cabinet with a power consumption of around $10 \mathrm{~kW}$. That computer's CPU's are cooled by microchannel HE's designed by the LTCM lab and are similar to those tested here (the present two-phase HE's have a smaller inlet orifice at each channel to effect good flow distribution and stable flow). The simulation of a vapor compression cooling cycle showed higher pumping power consumption when compared with the other cycles simulated; however, this cycle can be justified when the waste heat at the condenser is recovered for applications such as district heating and preheating of boiler feedwater. The highest condensing temperature (higher secondary fluid temperature) and heat transfer rate (associated with the work imparted by the compressor) represents a higher economic value than that obtained with the liquid pumping cooling cycles.

In summary, the main objectives of this paper are to show the development of control strategies for two different cooling systems using micro-evaporator elements (multi-microchannel evaporators or MEs) for direct cooling of the chips and memories on a blade server board and to compare the overall performance of the systems. The specific focus was to work with two-phase cooling using the dielectric refrigerant HFC134a, a liquid pump or a vapor compressor to drive the working fluid, a micro-evaporator for cooling of the chip and, for now, a simple tube-in-tube condenser for heat recovery, which can reduce the demand of cooling energy with respect to air cooling and water cooling by an impressive amount $[10,15]$. A multi-purpose test bench was constructed to experimentally evaluate the performance of the cooling systems under various typical blade server operating conditions of transient, steady state, balanced and unbalanced heat loads on the system's two pseudo CPU's, which in turn was directly cooled by means of micro-evaporators. Further, a preliminary exergy analysis was also performed, taking into account experimental results for the two-phase cooling systems operating at steady state conditions.

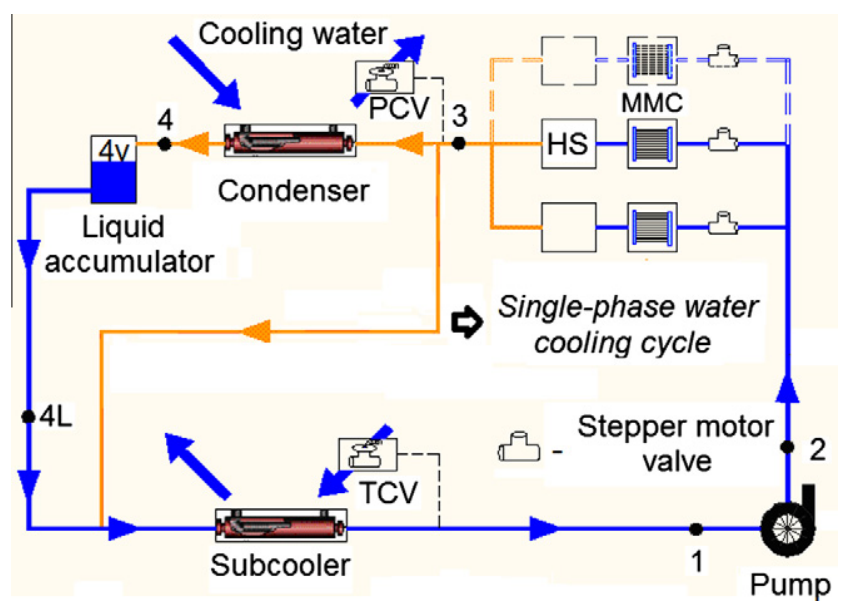

Fig. 1. Schematic of the liquid pumping cooling cycle.

\section{Experimental facility}

\subsection{Cooling cycle proposals and general considerations}

Figs. 1 and 2 depict potential two-phase cooling cycles, in which the cycle drivers are a liquid pump (LP cycle) and a vapor compressor (VC cycle), respectively [16]. The blue and orange lines ${ }^{2}$ in Fig. 1 represent the liquid and two-phase flows in the piping, respectively. The orange line also represents a by-pass when considering the single-phase water cooling cycle. In Fig. 2 the red line is superheated vapor piping, the orange line is piping with saturated liquid and subcooled liquid at high pressure and blue line is piping with subcooled liquid, saturated fluid and saturated vapor all at low pressure.

The goal is to control the chip temperature to a pre-established level by controlling the inlet conditions of the multi-microchannel cooler (pressure, subcooling and mass flow rate). It is imperative to keep the multi-microchannel cooler outlet vapor quality below that of the critical vapor quality, which is associated with the critical heat flux. Due to this exit vapor quality limitation (it was decided not to surpass one-half of the critical vapor quality at the evaporator exit as a tentative safety margin), additional latent heat is available for further two-phase cooling in the server, which can be safely done for other low heat flux generating components, such as memory, DC/DC converters, etc.

Another parameter that must be controlled is the condensing pressure (condensing temperature). The aim is to recover the energy dissipated by the refrigerant in the condenser to heat buildings, residences, district heating, pre-heating boiler feedwater, etc. when it can be arranged and is viable.

The liquid pumping two-phase cooling cycle can be characterized by it having a low initial cost, a low vapor quality at the on-chip multi-microchannel cooler (MMC) outlet, a high overall efficiency, low maintenance costs and a low condensing temperature. The heat spreader (HS) is for cooling of memory, etc., which is shown as "one" cooler here for simplicity purposes. This is a good operating option when the energy dissipated in the condenser is not recovered, typically during the summer season. However, the heat can still be recovered if there is an appropriate demand for low quality heat (low exergy) at about $60^{\circ} \mathrm{C}$. On the other hand, the vapor compression cooling cycle can be characterized as having a high condensing temperature of up to $90-100{ }^{\circ} \mathrm{C}$ (high heat

\footnotetext{
${ }^{2}$ For interpretation of color in Figs. 1 and 2, the reader is referred to the web version of this article.
} 


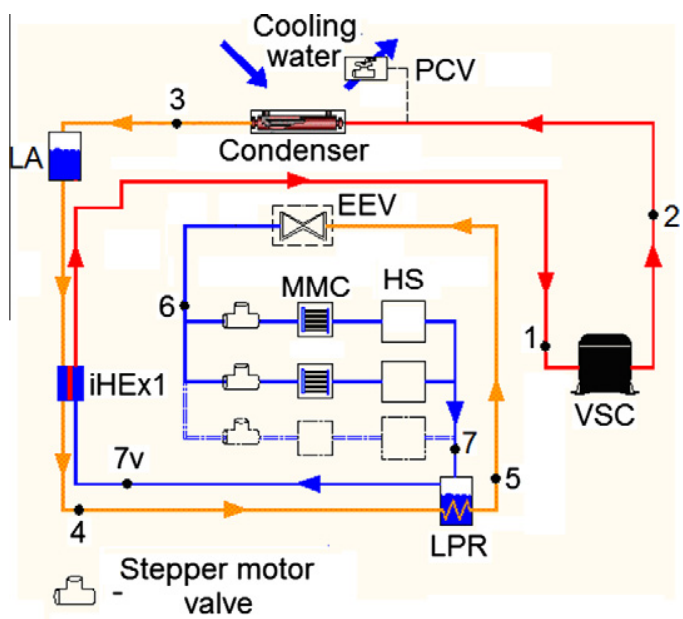

Fig. 2. Schematic of the vapor compression cooling cycle.

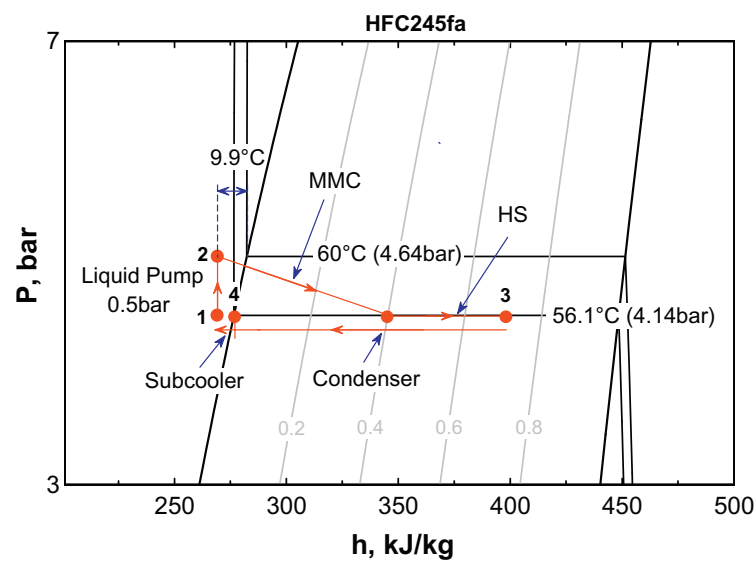

Fig. 3. P-h diagram of the liquid pumping cooling cycle.

recovery potential), a high range of controllability of the MMC inlet subcooling (characteristic of systems with variable speed compressors, VSC's, and electric expansion valves, EEV's), and a medium overall efficiency when compared with the liquid pumping cooling cycle. This is a good operating option when the energy dissipated in the condenser is recovered for other uses that require a higher temperature of the waste heat, typically during the winter season when considering a district heating application (high exergy).

Figs. 3 and 4 show the Mollier diagrams of the two cooling cycles for HFC245fa as the working fluid [16]. It can be noticed that the two cycles are differentiated mainly by the condensing temperatures with the evaporating temperature of the MMC set at $60^{\circ} \mathrm{C}$ (sufficient to keep the CPU below $85^{\circ} \mathrm{C}$ ).

It is worth mentioning that the applicability of these cooling cycles is not restricted to only one microprocessor but can be applied to blade servers and clusters, which may have up to 70 blades per rack. Each blade, such as that of IBM shown in Fig. 5, can have two or more microprocessors with a heat generation capacity of about $90 \mathrm{~W}$ each. If the auxiliary electronics (memories, DC/DC, etc.) on the blade are included, the total heat generation per blade can be $350 \mathrm{~W}$ or more. Thus, the heat spreader (HS), shown earlier in Figs. 1 and 2, has the function to cool the auxiliary electronics, which can represent about $50 \%$ of the total heat load on the blade, but will have a larger surface area compared to the CPU and thus a lower heat flux.

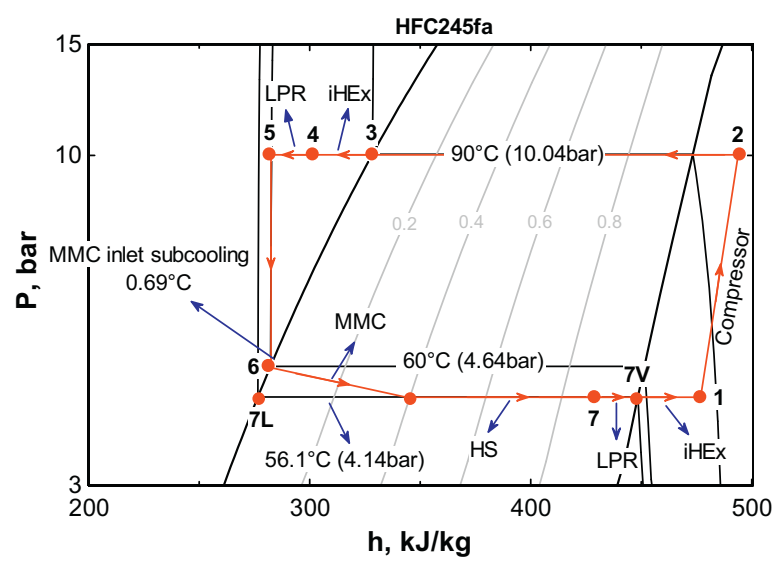

Fig. 4. P-h diagram of the vapor compression cooling cycle.

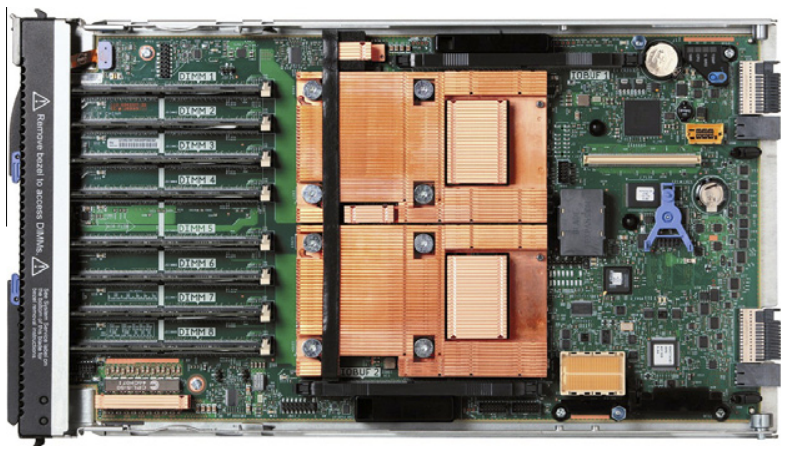

Fig. 5. IBM blade with two microprocessors and heat generation capacity of $350 \mathrm{~W}$ [25].

Consequently, when considering an entire rack, a very sizable heat load is generated, representing a good opportunity to recover the heat rejected. In this case, reuse of the heat removed from the blades for a secondary application will greatly reduce the $\mathrm{CO}_{2}$ footprint of the system. For example, if we consider a data center with 50 racks packed with high density blade servers ( 70 per rack), with each blade dissipating $350 \mathrm{~W}$, the total potential heat to be recovered is $1.225 \mathrm{MW}$. Such a heat recovery system requires a secondary heat transfer fluid to pass through all the condensers (either water or a refrigerant) to transport the heat to its destination (to the environment or into a heat recovery system).

\subsection{Cooling cycle assembly and instrument uncertainties}

The liquid pumping and vapor compression cooling cycles described above were built and experimentally evaluated in the present study, investigating the cooling system's energy consumption, exergetic efficiency and controllability. For such an evaluation, specific controllers were first designed and tested. The variables to be controlled were the MEs outlet vapor quality, the condensing pressure (LP cycle) and the temperature difference between the water outlet flow and working fluid inlet flow in the condenser (VC cycle). The actuators used were the vapor compressor, the condenser water pump and the stepper motor valve (over-dimensioned to modulate the refrigerant mass flow with a negligible pressure drop). Two MEs in parallel (typical for blade servers with two CPU's) assembled on pseudo chips, each composed of 35 heaters and temperature sensors ( $2.5 \mathrm{~mm}$ by $2.5 \mathrm{~mm}$ in size), were used. The MEs' copper microchannel geometry consisted of 53 channels having a height of $1.7 \mathrm{~mm}$ and a width of $0.17 \mathrm{~mm}$, with the 
Table 1

Instruments uncertainty.

\begin{tabular}{|c|c|c|}
\hline Instrument & Range & Uncertainty \\
\hline Thermocouple at ME1 inlet $\left(T_{i}\right)-{ }^{\circ} \mathrm{C}$ & $10-100$ & \pm 0.20 \\
\hline Pressure transducer at ME1 inlet $\left(P_{i}\right)$, bar & $0-20$ & \pm 0.004 \\
\hline Thermocouple at ME1 outlet $\left(T_{o}\right)-{ }^{\circ} \mathrm{C}$ & $10-100$ & \pm 0.19 \\
\hline $\begin{array}{l}\text { Differential pressure transducer at ME1, } \\
\text { bar }\end{array}$ & $0-0.2$ & \pm 0.00058 \\
\hline Thermocouple at ME2 inlet $\left(T_{i}\right)-{ }^{\circ} \mathrm{C}$ & $10-100$ & \pm 0.21 \\
\hline Pressure transducer at ME2 inlet $\left(P_{i}\right)$, bar & $0-20$ & \pm 0.009 \\
\hline Thermocouple at ME2 outlet $\left(T_{o}\right)-{ }^{\circ} \mathrm{C}$ & $10-100$ & \pm 0.19 \\
\hline $\begin{array}{l}\text { Differential pressure transducer at ME2, } \\
\text { bar }\end{array}$ & $0-0.2$ & \pm 0.00069 \\
\hline Outlet vapor quality, $\%$ & $0-100$ & \pm 0.5 \\
\hline Power supply for pseudo chip 1 and 2, W & $0-100$ & $\begin{array}{l} \pm 1.0 \% \text { Of the } \\
\text { measured value }\end{array}$ \\
\hline Coriolis mass flow meter, $\mathrm{kg} / \mathrm{h}$ & $0-108$ & \pm 0.05 \\
\hline Power transducers of minicompressor, $\mathrm{W}$ & $0-125$ & $\begin{array}{l} \pm 0.5 \% \text { of the } \\
\text { measured value }\end{array}$ \\
\hline Power transducers of gear pump, W & $0-1150$ & $\begin{array}{l} \pm 0.5 \% \text { of the } \\
\text { measured value }\end{array}$ \\
\hline $\begin{array}{l}\text { Power transducers of expansion valves, } \\
\text { W }\end{array}$ & $0-37.5$ & $\begin{array}{l} \pm 0.5 \% \text { Of the } \\
\text { measured value }\end{array}$ \\
\hline $\begin{array}{l}\text { Turbine meter for secondary fluid at the } \\
\text { condenser, } \mathrm{L} / \mathrm{min}\end{array}$ & $\begin{array}{l}0.0450- \\
0.4280\end{array}$ & \pm 0.0023 \\
\hline
\end{tabular}

spacing between channels being $0.17 \mathrm{~mm}$ (the same as in the Aquasar project mentioned earlier). The effective "footprint" area of the MEs is $12 \mathrm{~mm}$ length and $18 \mathrm{~mm}$ width. The pseudo chip/ ME assembly has been extensively tested to study flow boiling heat transfer, two-phase pressure drops, hot spot cooling with non-uniform heat fluxes, transient cooling, etc. by Costa-Patry et al. [17-19]. However, in the present work only uniform heat fluxes were considered. HFC134a was tested as the working fluid and an oil free mini-compressor (supplied by Embraco of Joinville, Brazil) and a gear pump as drivers. It is important to highlight the characteristic "oil free" operation, which is mandatory for operation of micro-evaporation cooling systems and is considered as an advantage of the new mini-compressor.

Table 1 shows the measuring instruments installed in the experimental facility together with the uncertainties obtained through calibration. The method proposed by Kline and McClintock [20] was used to determine the uncertainties. The uncertainty of the vapor quality is also shown and was determined by means of the propagation of errors due to the power transducer, Coriolis mass flow meter, differential and absolute pressure transducers and K-type thermocouples. Eqs. (1) and (2) show the method used to determine the ME outlet vapor quality. All thermodynamic properties were determined from the Refprop [21] database. Finally, all data were captured by means of a data acquisition system making use of the LabVIEW software. The data acquisition time, essential for the controllers' design, was fixed at $0.75 \mathrm{~s}$ (each acquisition considered 850 samples per channel at a rate of $1000 \mathrm{~Hz}$ ).

$x_{0}=f\left(h_{0}, p_{o}\right)$ determined from Refprop

$h_{0}=\frac{\dot{W}_{\text {input }}}{\dot{m}}+h_{i}$, where $h_{i}=f\left(P_{i}, T_{i}\right)$ determined from Refprop

\section{Control system}

\subsection{Liquid pumping cooling system}

\subsubsection{Component controllers}

The first controller developed was for modulating the condenser liquid pump speed (LPS), i.e. the water (secondary fluid) flow rate to the condenser, in order to maintain the condensing pressure $(\mathrm{Pc})$ at the set point value $\left(\mathrm{Pc}_{\mathrm{sp}}\right)$. The second controller was developed to control the MEs' outlet vapor quality $\left(x_{o}\right)$, but with the modulation of the stepper-motor-valve aperture $\left(A_{\mathrm{SMV}}\right)$. This was achieved by deriving mathematical models capable of representing the dynamic behavior of the system under consideration by means of a system identification process and a PI structure that was used for the controllers since the system showed low order dynamics.

The system identification, controller design and preliminary evaluation by tracking tests, which are conventional steps in the development of new controllers, are presented below. In sequence, a deeper evaluation of the controllers operating together is shown for what was named a dual SISO control strategy, which does not consider the coupling effects between the controlled variables. Such a strategy was evaluated by disturbance rejection and flow distribution tests; for the latter the effect of different heat loads applied on the two micro-evaporators is investigated.

3.1.1.1. LPS controller: system identification and controller design. Fig. 6 illustrates the block diagram of the first control loop, where the condensing pressure (Pc) is the controlled variable $\left(\mathrm{Pc}_{s p}\right.$ is the set point) and the condenser liquid pump speed (LPS) is the manipulated variable.

The system identification process has the objective of deriving a mathematical model capable of representing the dynamic behavior of the system. A linear first-order model with delay was used to correlate Pc with the LPS variations. The condensing pressure was measured with a calibrated pressure transducer at the inlet of the condenser. For such a system, the pressure drop between the inlet of MEs and inlet of condenser is negligible ( $<0.03$ bar), so the condensing pressure controller can also be considered as an evaporating pressure controller. Eqs. (3) and (4) show the model in the time and Laplace domains, respectively:

$\tau \frac{d y(t)}{d t}+y(t)=K_{p} u(t-\theta)$

$G(s)=\frac{y(s)}{u(s)}=\frac{K_{p} e^{e^{-\theta s}}}{\tau s+1}$

The input $(u)$ and output $(y)$ parameters are LPS and Pc, respectively, while $G$ is the transfer function, $\tau$ the system time constant, $K_{P}$ the gain and $\theta$ the transport delay.

The model parameters were obtained by varying the LPS from $1620 \mathrm{rpm}$ to $1800 \mathrm{rpm}$ (step response experiment, viz. Fig. 7). The cycle's liquid pump speed, the water temperature (secondary fluid) at the inlet of condenser, the SMV's aperture and the heat load on the MEs were maintained at $3000 \mathrm{rpm}, 40{ }^{\circ} \mathrm{C}, 25 \%$, and $90 \mathrm{~W}$ for ME1 and $75 \mathrm{~W}$ for ME2, respectively. These operating conditions are from now on referred to as the standard conditions.

It is important to mention that during the initial tests it was observed that the subcooler was redundant for this cycle and level of heat load investigated. This was due to the heat losses in the piping, which ensured that there was always enough subcooling at the inlet of the liquid pump and micro-evaporators. Such a situation might not be the same for the case of better piping insulation and higher heat load, as for an entire blade center (e.g. IBM blade center QS22 with a heat load of about $5000 \mathrm{~W}$ ). The subcooling at the inlet manifold of the MEs in all evaluations considered in this work remained between 2 and $8 \mathrm{~K}$, avoiding the necessity for special controllers to avoid saturation conditions (that is, unwanted vapor in the inlet header of ME1 and ME2), which would otherwise jeopardize the MEs' performance by creation of flow maldistribution.

The model parameters $K_{P}, \tau$ and $\theta$ were estimated in order to minimize the square error between the model predictions and 


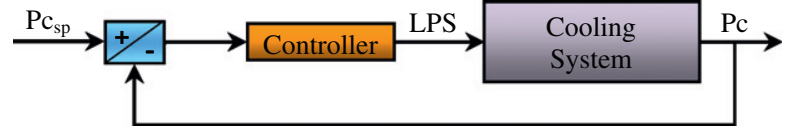

Fig. 6. LPS controller.

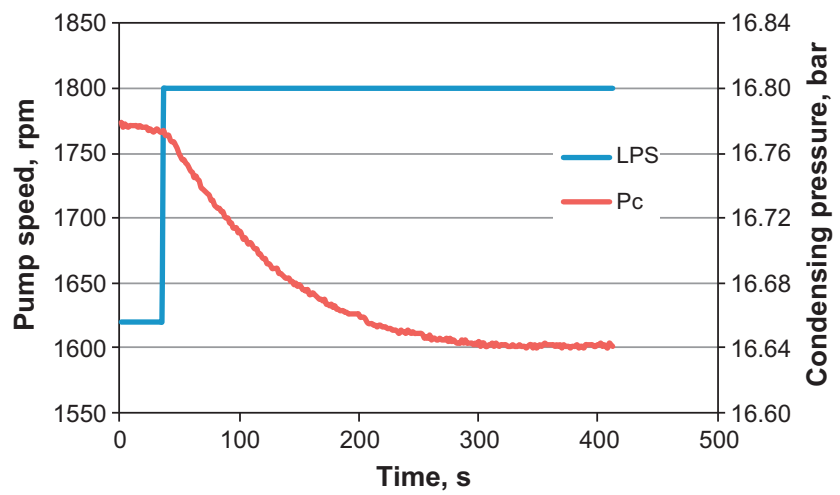

Fig. 7. LPS - model identification. (For interpretation of the references to colour in this figure legend, the reader is referred to the web version of this article.)

the experimental data. For this controller $K_{P}, \tau$ and $\theta$ were estimated as $-0.8 \mathrm{mbar} / \mathrm{rpm}, 90.85 \mathrm{~s}$ and $2.59 \mathrm{~s}$, respectively. Figs. 7 and 8 depict part of the identification tests, showing the Pc response to a step change in the LPS and also the Pc model predictions against the experimental data.

As mentioned beforehand, the PI structure was selected for this study. Eq. (5) shows the PI controller transfer function in the Laplace domain:

$C(s)=K_{C}\left(1+\frac{1}{T_{I} S}\right)$

The PI controller was designed using the method proposed by [22], which is based on linear programming. It was computed to guarantee a phase margin of $30^{\circ}$, a gain margin of 2 and a crossover frequency two times larger than in an open loop. The $T_{I}$ (integral time) and $K_{C}$ (proportional) parameters were calculated as $90.85 \mathrm{~s}$ and $-9816 \mathrm{bar} / \mathrm{rpm}$, respectively.

3.1.1.2. Controller evaluation. Tracking tests were carried out with the experimental apparatus running under the standard operating conditions to evaluate the controller performance. Figs. 9 and 10 show the results for five steps in the pressure set point between 16.8 bar and 17.0 bar for the LPS controller. As can be noticed, the controller increased or decreased the liquid pump speed, in response to a decrease or increase in the pressure set point value.

The results showed that the controller is effective and efficient to track the set point of pressure in a short time $(\cong 3.5 \mathrm{~min}$ after step 6 , viz. Fig. 11) with a maximum overshoot in the condensing temperature of only about $0.16^{\circ} \mathrm{C}$ (viz. Fig. 9).

3.1.1.3. SMV controller: system identification and controller's design and evaluation. The controller developed for the MEs' outlet vapor quality considered the SMV as the actuator. The vapor quality of the flow after the outlet of the MEs was used for control. It is worth mentioning that this variable has a considerable effect on the performance of the ME [23], and as a consequence on the overall system. Therefore, for safe operating reasons, such a controller must avoid the critical vapor quality, a condition where the pseudo chips could be damaged due to dryout occurring. Fig. 12 illustrates the controller's block diagram.

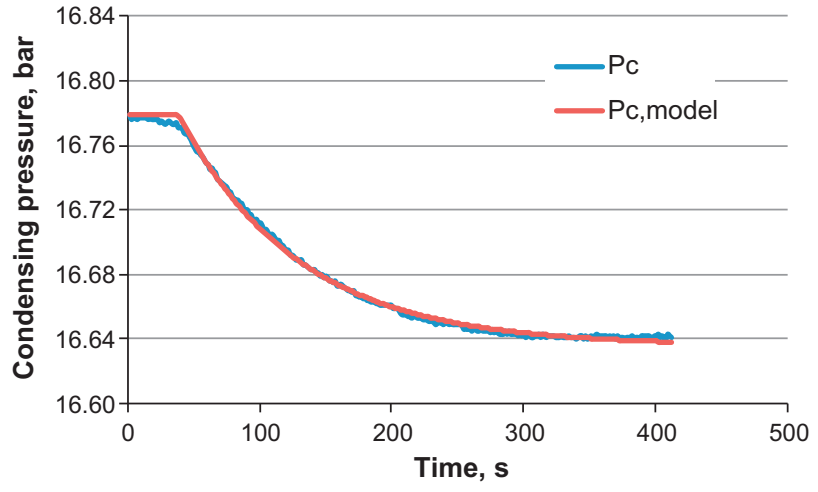

Fig. 8. LPS - experimental vs. prediction. (For interpretation of the references to colour in this figure legend, the reader is referred to the web version of this article.)

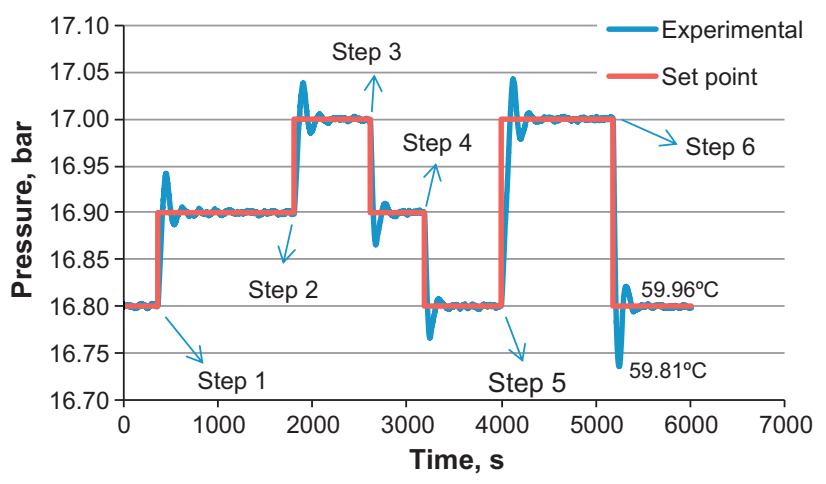

Fig. 9. Pc variation. (For interpretation of the references to colour in this figure legend, the reader is referred to the web version of this article.)

The system identification was developed considering the standard conditions as a starting point and a change in SMV aperture of $2 \%$ each 10 s between $22 \%$ and $40 \%$ of aperture. The average of vapor quality for the last $5 \mathrm{~s}$ of each change was considered as the value for each aperture, i.e. the values shown in Fig. 13. It is important mentioning that the vapor quality was calculated/determined for each acquisition time by an energy balance enclosing the MEs, where the heat load, mass flow rate and inlet/outlet pressures and temperatures required for this calculation, were measured with calibrated transducers.

During the system identification it was observed that small changes in the aperture resulted in a fast response $(2 \mathrm{~s} \ldots 3 \mathrm{~s})$ in the exit vapor quality, as can be seen in Fig. 14. Thus, the model of the system was approximated by its static gain $\left(K_{P}\right)$, which varied nonlinearly with the SMV aperture change, as can be seen below:

$$
\begin{aligned}
K_{p}= & \frac{\partial X}{\partial S M V} \\
= & -7.8 \times 10^{-6} \mathrm{SMV}^{4}+10.4 \times 10^{-4} \mathrm{SMV}^{3}-5.2 \times \mathrm{SMV}^{2} \\
& +1.16 \mathrm{SMV}-9.63
\end{aligned}
$$

Therefore, a gain-scheduled PI controller was developed whose gain was a function of the SMV aperture. That is, the closed-loop transfer function was represented by Eq. (7), where the time constant $(\tau)$ is given by Eq. (8):

$$
H(s)=\frac{x_{o}}{\chi_{o, s p}}=\frac{\frac{K_{c}}{K_{i}} s+1\{\text { zeros }}{\frac{s\left(1+K_{c} \cdot K_{p}\right)}{K_{i} \cdot K_{p}}+1\{\text { poles }}
$$




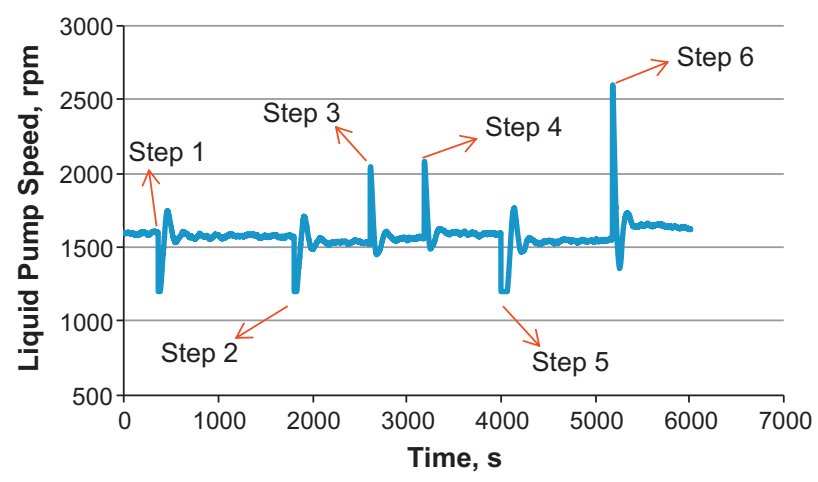

Fig. 10. LPS variation.

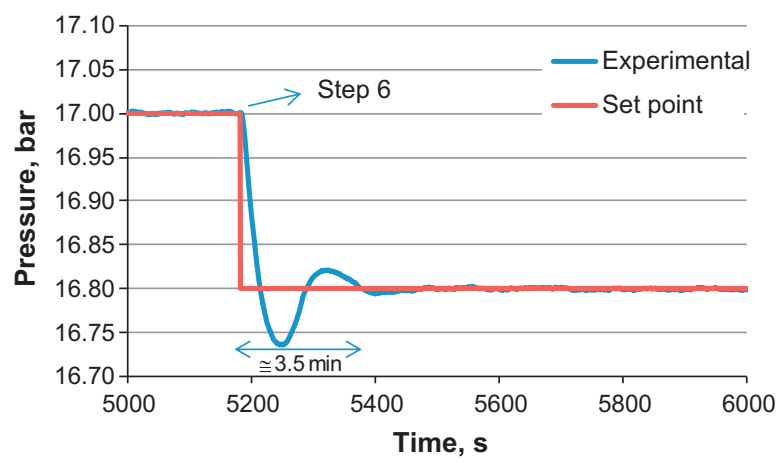

Fig. 11. Pc variation for step 6. (For interpretation of the references to colour in this figure legend, the reader is referred to the web version of this article.)

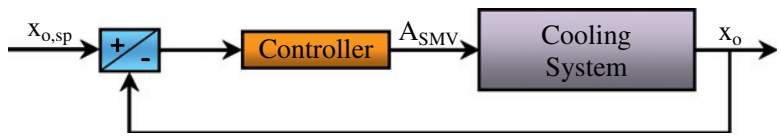

Fig. 12. SMV controller.

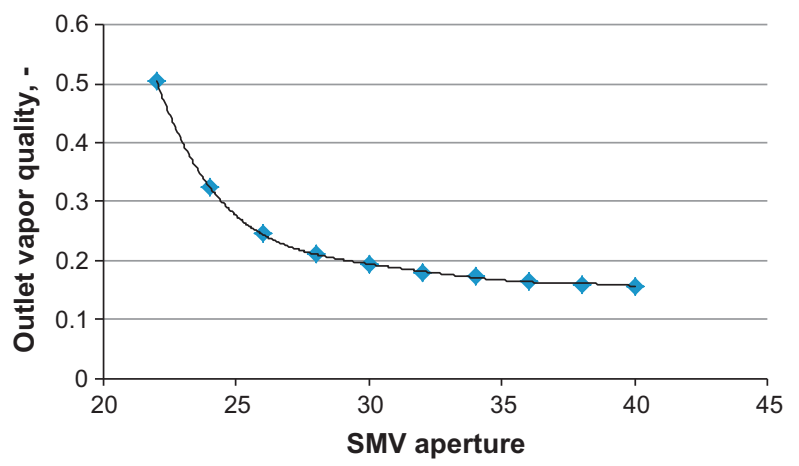

Fig. 13. System identification: xo vs. SMV aperture.

$\tau=\frac{1+K_{c} \cdot K_{p}}{K_{i} \cdot K_{p}}$

Defining $\tau_{D}$ as the desired closed-loop time constant, and $C$ as a parameter relating the closed-loop pole $(p)$ and zero $(z)$ such that $p=C . z$, Eqs. (9) and (10) were obtained for the integral and proportional constants, i.e. $K_{I}$ and $K_{C}$ :

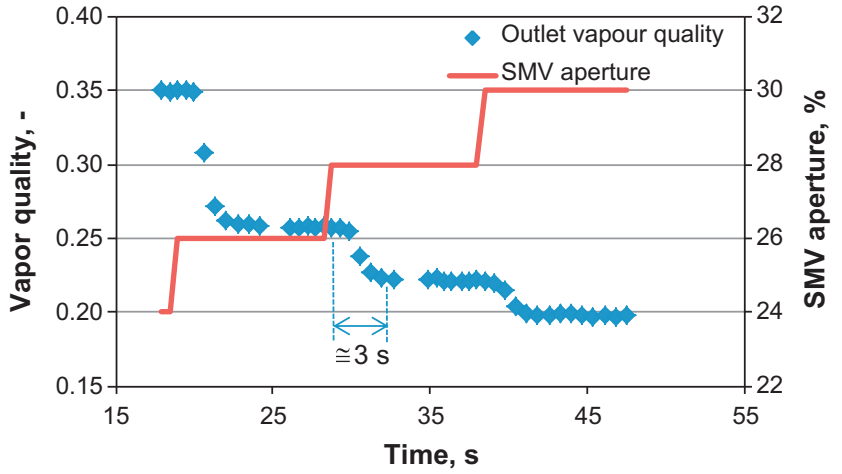

Fig. 14. System identification: response time of exit vapor quality by changing the SMV aperture.

$$
\begin{aligned}
& K_{C}=\frac{1}{(C-1) \cdot K_{p}} \\
& K_{I}=\frac{C}{C-1} \cdot \frac{1}{\tau_{D} \cdot K_{p}}=\frac{T_{I}}{K_{C}}
\end{aligned}
$$

The gains $K_{I}$ and $K_{C}$ of the controller are functions of the static gain of the system $K_{P}$ and are updated during runtime. $C$ and $\tau_{D}$ can be seen as tuning parameters, which were experimentally adjusted for 15 and $5 \mathrm{~s}$, respectively. Moreover, an anti-wind up strategy was implemented to reduce the accumulated integral error of the controller when the output of the controller moved outside the SMV's range (22-40\% of aperture). It is worth highlighting that other techniques to design the gain-scheduled controller could also be used, for example, the method proposed in [24].

Fig. 15 shows the outlet vapor quality tracking test, where it can be seen that the controller reacted fairly quickly for the 4 steps considered. In the worst case, the controller took about 30 s to stabilize the system; however only a small overshoot was observed, i.e. a maximum of $1.5 \%$ in vapor quality. Finally, it can be concluded that the controller was efficient and effective for the actual application, showing a small overshoot and settling time.

\subsubsection{Dual SISO controller}

The dual SISO control strategy was derived from the two individual controllers, as illustrated in the block diagram of Fig. 16. This allowed the simultaneous control of Pc and $x_{o}$ to match the thermal load with the cooling capacity for the condensing temperature and vapor quality desired.

Disturbance rejection and flow distribution tests were performed with the experimental apparatus running under a standard operating condition to evaluate the controllers' performance. In these tests, after the apparatus was in a steady-state regime, the input power on the pseudo chips (heat load on the MEs) was changed periodically for a constant period of time between two levels for the disturbance rejection tests and changed to different levels until the steady state condition was established for the flow distribution tests, as will be shown below.

3.1.2.1. Heat load disturbance rejection. The integrated controller or decentralized control structure was first evaluated by considering the standard conditions at the beginning of the test, and a set point of condensing pressure $\left(\mathrm{Pc}_{s p}\right)$ and outlet vapor quality of $16.8 \mathrm{bar}$ and $22 \%$, respectively. The performance of the control strategies regarding disturbance rejections was evaluated by periodically changing the heat load on the micro-evaporators. As the heat load changed, so did the condensing pressure and vapor quality disturbances, which were detected automatically by the controllers. These in turn increased or decreased the LPS and SMV aperture to maintain the pressure and vapor quality at the set point. 


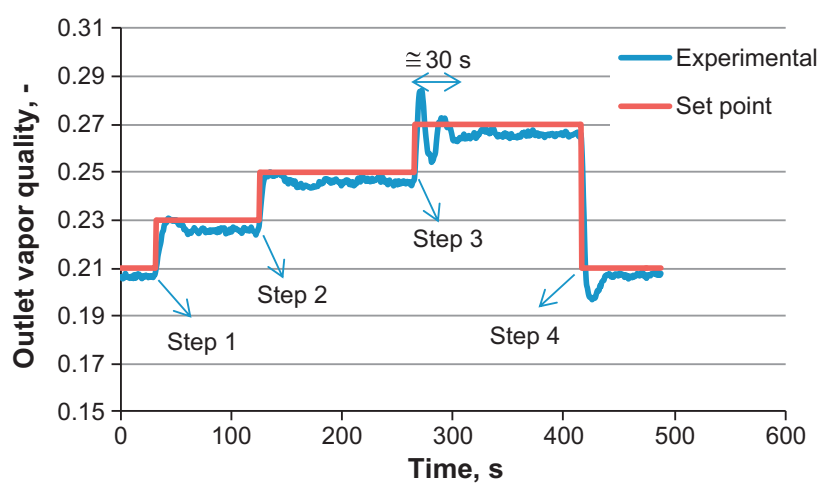

Fig. 15. Outlet vapor quality tracking test. (For interpretation of the references to colour in this figure legend, the reader is referred to the web version of this article.)

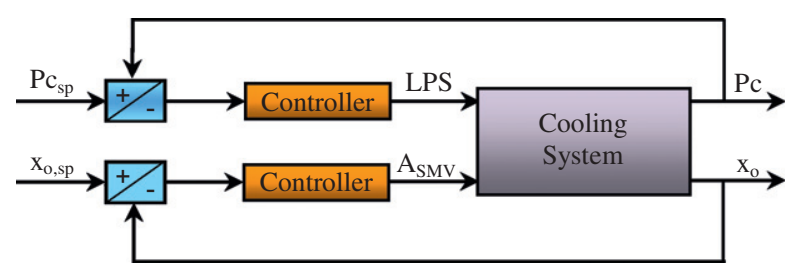

Fig. 16. The dual SISO controller.

The heat load on ME1 and ME2 were changed between $90 \mathrm{~W}$ and $75 \mathrm{~W}$ and $75 \mathrm{~W}$ and $60 \mathrm{~W}$, respectively, considering a periodic disturbance time of $1.4 \mathrm{~s}$. Fig. 17 shows the input power disturbance on the pseudo chips and the effect on the average temperature of each chip. This temperature was obtained by averaging the temperature from 11 well distributed sensors on each chip. It can be observed that there was a maximum temperature variation of $1.5^{\circ} \mathrm{C}$, which can be considered to be acceptable when compared to the temperature gradient along the chip for on-chip singlephase cooling using water (about 2-3 K [12-14]).

Figs. 18 and 19 show the controllers' reaction under the situation of a disturbance. It can be seen that the SMV controller was able to maintain the exit vapor quality to within $\pm 5 \%$ of the set point. What is important to observe is that the controller was effective, i.e. it showed fast response for the induced disturbance and no instability was observed.

The LPS controller (viz. Fig. 19) showed an initial offset when the heat load disturbance started, which represents a condensing temperature deviation of only 0.05 bar or $0.1^{\circ} \mathrm{C}$ (it also represents a very small evaporating temperature variation) and it can be seen that the controller was able to reset the offset after about $2.5 \mathrm{~min}$. Once again the controller proved to be effective and efficient in maintaining the set point.

3.1.2.2. Flow distribution for non-uniform heat load. To evaluate the effect of a non-uniform heat load applied to the two MEs on the flow distribution and, consequently, on the pseudo chips' temperature and performance of the controllers, tests were developed for different heat loads between $30 \mathrm{~W}$ and $90 \mathrm{~W}$ and set points of outlet vapor quality between $15 \%$ and $22 \%$. A total of eight different combinations of such heat loads and three outlet vapor qualities were evaluated, as can be seen in Figs. 20 and 21.

The tests started with the standard conditions, a set point of condensing pressure and outlet vapor quality of 16.8 bar and $22 \%$, and heat loads on ME1 and ME2 of $90 \mathrm{~W}$ and $75 \mathrm{~W}$, respectively. Seven steps of heat load combinations were then imposed, with the last one considering three different vapor quality set points; $22 \%, 18 \%$ and $15 \%$. The steady state condition was obtained before each new change in heat load or set point of vapor quality. Figs. 21

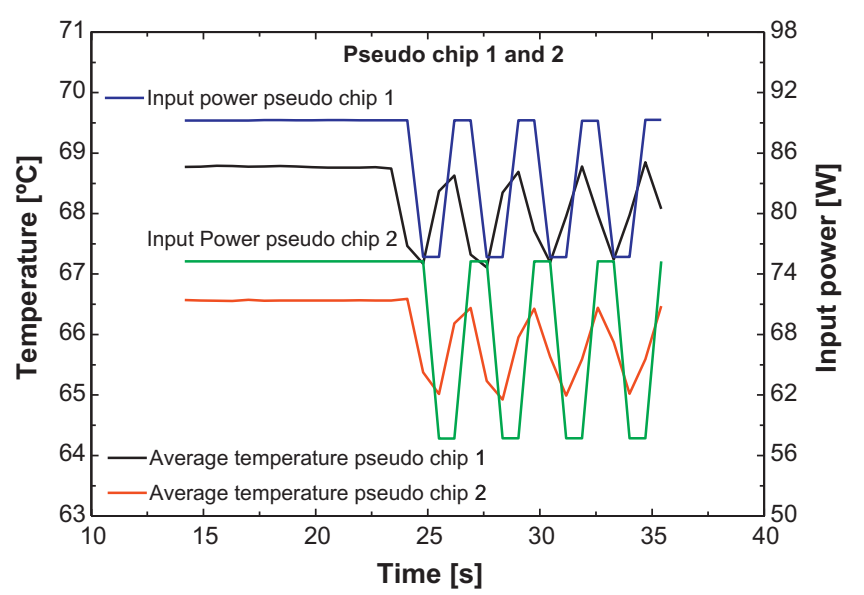

Fig. 17. Heat load disturbance and pseudo chip temperatures. (For interpretation of the references to colour in this figure legend, the reader is referred to the web version of this article.)

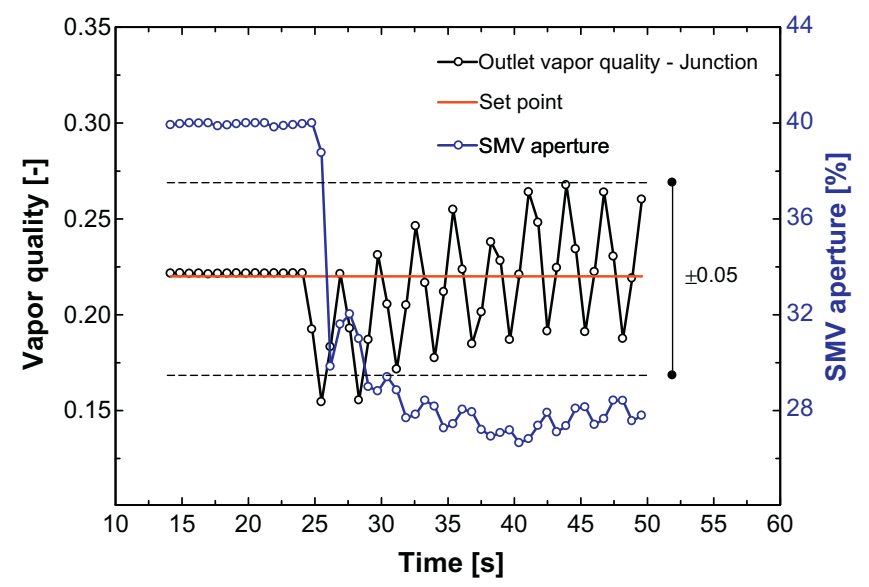

Fig. 18. Outlet vapor quality and SMV controller. (For interpretation of the references to colour in this figure legend, the reader is referred to the web version of this article.)

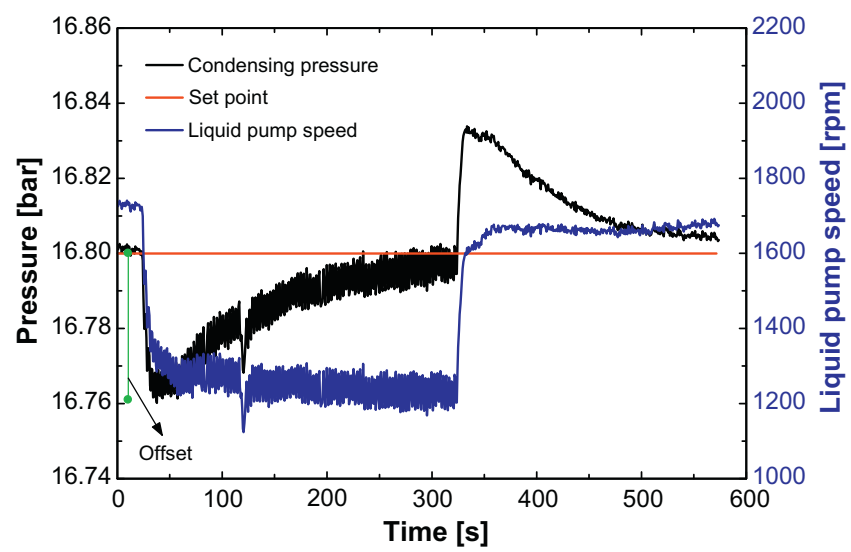

Fig. 19. Condensing pressure and LPS controller. (For interpretation of the references to colour in this figure legend, the reader is referred to the web version of this article.)

and 22 show the results obtained for the average temperature on the pseudo chips, the MEs' outlet vapor qualities and the SMV aperture (action of the controller). 
Firstly, it can be seen that the SMV controller was effective and efficient in controlling the outlet vapor quality under different conditions of heat load and set points of exit vapor quality. The controller proved to be very fast in reaching the steady state condition, with the maximum transient time observed to be about $30 \mathrm{~s}$ in step 7, all the while maintaining the pseudo CPU average temperatures well below $85^{\circ} \mathrm{C}$ (typically upper operational limit).

Regarding the pseudo chips' temperatures (viz. Fig. 21), the following aspects were observed

(a) For the same heat load, step 2, the average temperature of both pseudo chips was the same, i.e. about $67^{\circ} \mathrm{C}$. This implies that the distributors (piping) before and after the MEs were well designed and that both MEs have the same mass flow rate.

(b) The maximum temperature difference observed was, as expected, in step 7, which considered $90 \mathrm{~W}$ on chip 1 and $30 \mathrm{~W}$ on chip 2 . A difference of $14.5^{\circ} \mathrm{C}$ was obtained, where chip 1 reached a temperature of $75^{\circ} \mathrm{C}$ vs. $60.5^{\circ} \mathrm{C}$ on chip 2 . Despite this difference, the limit of $85^{\circ} \mathrm{C}$ is still very far away.

(c) The chips' temperature difference and the absolute temperatures were reduced when the set point of the outlet vapor quality was reduced. A difference of $11.5^{\circ} \mathrm{C}$ and a temperature of $71.5^{\circ} \mathrm{C}$ were obtained for chip 1 when the outlet vapor quality set point was reduced to $15 \%$.

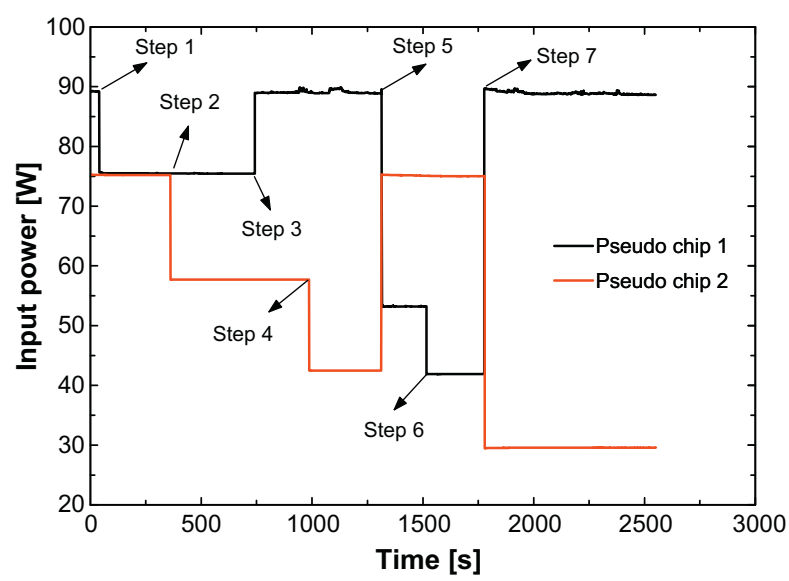

Fig. 20. Different heat loads on the MEs. (For interpretation of the references to colour in this figure legend, the reader is referred to the web version of this article.)

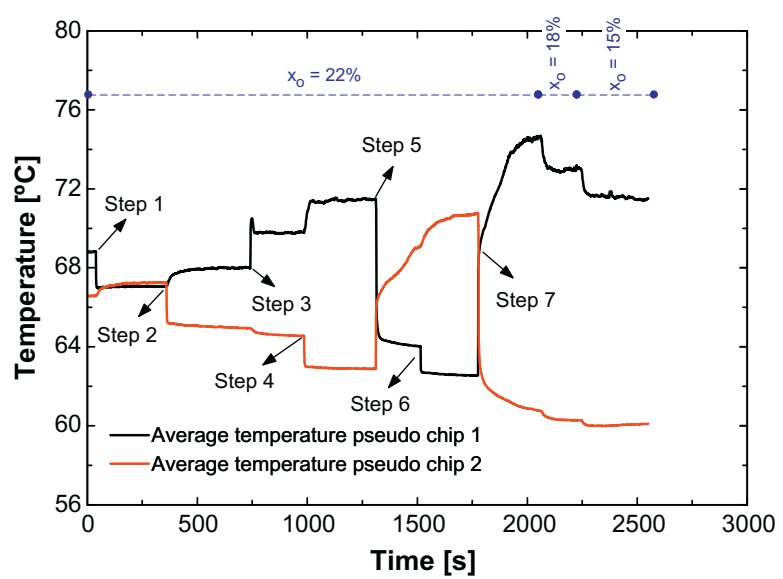

Fig. 21. Average temperature on the pseudo chips. (For interpretation of the references to colour in this figure legend, the reader is referred to the web version of this article.)

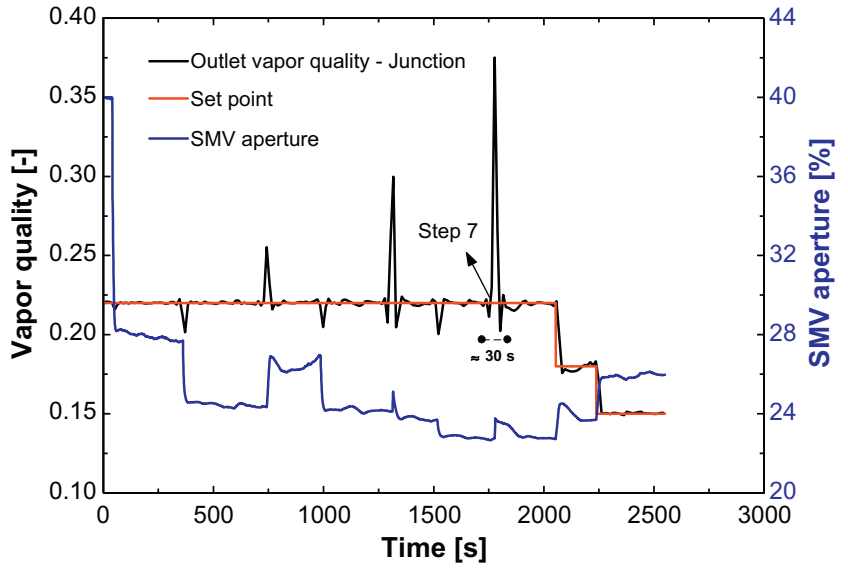

Fig. 22. Outlet vapor quality and SMV aperture. (For interpretation of the references to colour in this figure legend, the reader is referred to the web version of this article.)

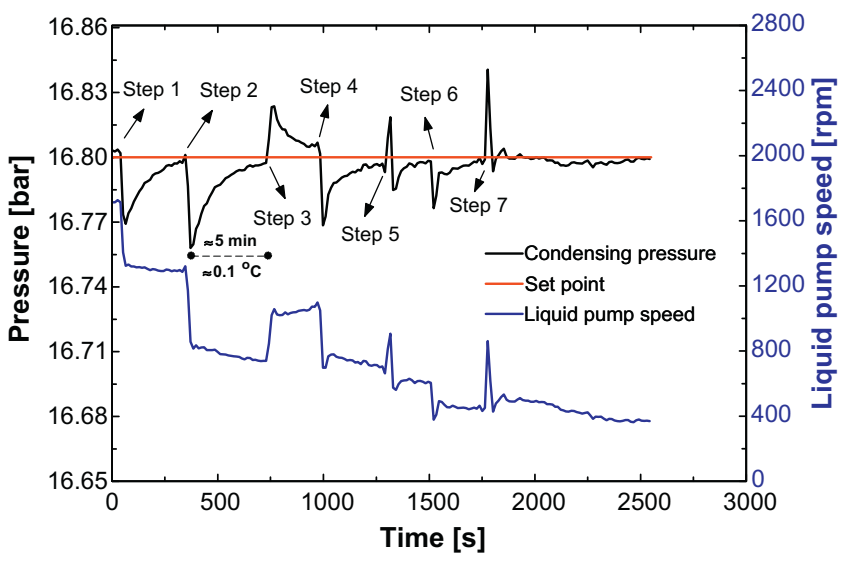

Fig. 23. Condensing pressure and LPS. (For interpretation of the references to colour in this figure legend, the reader is referred to the web version of this article.)

Fig. 23 shows the effect of a non-uniform heat load on the LPS controller. It can be seen that for all ranges of heat loads investigated, the controller was able to control and stabilize the condensing pressure at the set point. The maximum disturbance observed was stabilized after $5 \mathrm{~min}$ and provoked an overshoot of only $0.1^{\circ} \mathrm{C}$ in the condensing temperature.

Finally, it can be highlighted that the dual SISO strategy proved to be a simple and effective way of controlling the condensing pressure and vapor quality while maintaining the pseudo chips within a safe operating range. The coupling effect between the two controllable variables was not strong, in other words the controllers have low interaction effects, implying that it was not necessary to apply a more complex centralized MIMO controller.

\subsection{Vapor compression cooling system}

\subsubsection{Component controllers}

For the vapor compression cooling system, alternative control strategies were adopted due to its cooling cycle concept being different. In this system, the objective is not only to cool the pseudo chips but also to recover the energy removed in the condenser, since a higher condensing temperature is possible to be obtained (higher exergy thus available). From this point of view, the difference in temperature between outlet water flow and inlet working fluid flow in the condenser $\left(\Delta T_{c}\right)$ and the MEs' outlet vapor quality were defined as the variables to be controlled. The manipulated 
variables were, for the former, the LPS and for the latter the SMV aperture and the mini-compressor stroke length. It is worth mentioning that preliminary evaluations for the LPS controlling the condensing pressure were developed, as used in the liquid pumping cooling system. However, this variable showed a strong coupling with the outlet vapor quality, which provoked instabilities in the system when the controllers were operated together.

The SMV was used as an expansion device (EEV in Fig. 2) and also as an actuator to control the outlet vapor quality together with the mini-compressor. The results obtained in this work, as will be shown, proved that since the system is well designed and controlled, a SMV for each ME is not necessary, as was initially proposed by [16] and schematically given in Fig. 2, i.e. only one SMV or EEV is sufficient to operate as an expansion device and actuator for the outlet vapor quality controller. It should be mentioned that this is probably only valid when two MEs are considered (only one blade), with a more general statement only being valid once a complete blade center has been evaluated. The mini-compressor is a linear oil-free compressor capable of modulating the volumetric displacement, here defined as the stroke, according to the manufacturer's scale, between zero and ten.

Regarding the thermodynamic conditions at the inlet of the mini-compressor and MEs, all tests presented in this work showed superheating and subcooling conditions, respectively. The values remained between $1 \mathrm{~K}$ and $10 \mathrm{~K}$, and in the same way as was observed in the previous system, special controllers were not required to avoid saturation conditions. The reason is partly associated with the performance obtained by the iHEx and LPR components (viz. Fig. 2). As will be discussed below, they demonstrated a high exergetic efficiency and consequently ensured the conditions mentioned beforehand.

3.2.1.1. SMV and mini-compressor controllers. System identification, controller design and reference tracking evaluation were done, as for the previous system. To control the MEs' outlet vapor quality, the SMV aperture and the mini-compressor stroke were used as manipulating variables. Therefore, two PI controllers were designed independently. The SMV controller used the same strategy, i.e. a gain-scheduling PI controller whose parameters are actualized/updated for each acquisition time. The relationship between the manipulated and the controlled variables can be considered static, which is a function of the SMV and is given by (static gain $K_{P}$ ):

$$
\begin{aligned}
K_{p} & =\frac{\partial X}{\partial S M V} \\
& =3.5 \times 10^{-2} \mathrm{SMV}^{3}-1.1 \mathrm{SMV}^{2}+10.9 \mathrm{SMV}-36.2
\end{aligned}
$$

The gains of the controller are a function of the gain $K_{P}$ according to Eqs. (9) and (10). The desired closed-loop time constant was adjusted to $\tau_{D}=15 \mathrm{~s}$, the constant $C=35$ and the anti-wind up set to 0.5 . Due to the SMV operating as an expansion device, the range of operation was limited to between $6.5 \%$ and $9 \%$ of aperture.

For the mini-compressor controller, the transfer function obtained from the system identification is given by:

$G(s)=\frac{y(s)}{u(s)}=\frac{-0.0573 e^{-0.0741 s}}{8.23 s+1}$

Using the linear programming method proposed in [22] and considering a phase margin of $60^{\circ}$, a gain margin of 2 and a crossover frequency twice as large as in the open loop, the minicompressor's PI parameters, i.e. $K_{C}$ and $T_{I}$, were determined as $-34.3 \% /$ stroke and $8.23 \mathrm{~s}$, respectively.

3.2.1.2. LPS controller. To control the difference of temperature between outlet water flow and inlet working fluid flow in the condenser, i.e. $\Delta T_{c}$, the LPS was used as the manipulating variable.
The transfer function obtained from the system identification is given by Eq. (13), and the LPS controller parameters adjusted were $82.04{ }^{\circ} \mathrm{C} / \mathrm{rpm}$ and $33.76 \mathrm{~s}$, respectively for $K_{C}$ and $T_{I}$. The same criteria and method used for the design of the mini-compressor controller was used:

$G(s)=\frac{y(s)}{u(s)}=\frac{0.0234 e^{-0.01 s}}{33.76 s+1}$

3.2.1.3. Controller evaluation. A standard condition was defined to start each evaluation, i.e., mini-compressor stroke of 4, SMV aperture of $7.7 \%$, LPS of $1100 \mathrm{rpm}$, inlet water temperature in the condenser of $14^{\circ} \mathrm{C}$ and input heat loads of $75 \mathrm{~W}, 75 \mathrm{~W}$ and $150 \mathrm{~W}$ on pseudo chips 1 and 2, and on the post heater wrapped on the piping after the MEs (HS in the Fig. 2), respectively.

The post heater was necessary to guarantee superheated conditions at the inlet of the VSC and subcooled liquid at the inlet of the MEs. The post heater simulates the auxiliary electronics described beforehand and in [16]. A fixed value of $125 \mathrm{~W}$ was used, which, combined with the input power on the pseudo chips, added up to a total heat load of about $290 \mathrm{~W}$, which is equivalent to the heat load associated with IBM's QS22 blade.

Figs. 24 and 25 show the results for the MEs' outlet vapor quality tracking test, where $\Delta T_{c}$ was set to the value of $15 \mathrm{~K}$. The standard condition was defined as the starting point and six steps of vapor quality from $40 \%$ to $60 \%$ were investigated.

The outlet vapor quality proved to be well controlled by the two actuators operating together. It can be said that a negligible overshoot was observed and the controllers, mini-compressor and SMV, are efficient and effective in tracking the outlet vapor quality since no instabilities were observed in the outlet vapor quality. In the worst case, i.e. step 3, the controller took about $60 \mathrm{~s}$ to stabilize the system.

An anomalous operation was observed in the controller of the mini-compressor, as can be seen in Fig. 25. When the mini-compressor controller tried to increase the stroke, defined by the stroke controller, the actual stroke or stroke measured did not respond as defined by the controller. Such a situation was observed during steps 3, 4 and 5, and certainly has some negative effect in the performance of the controller, which was not observed in the present work probably due to the SMV controller compensating this deficiency. A possible reason is that the mini-compressor was not designed for such extreme operating conditions (evaporation of about $60^{\circ} \mathrm{C}$ and condensation of about $80^{\circ} \mathrm{C}$ compared to its normal design operating condition of about $5^{\circ} \mathrm{C}$ and $45^{\circ} \mathrm{C}$ ).

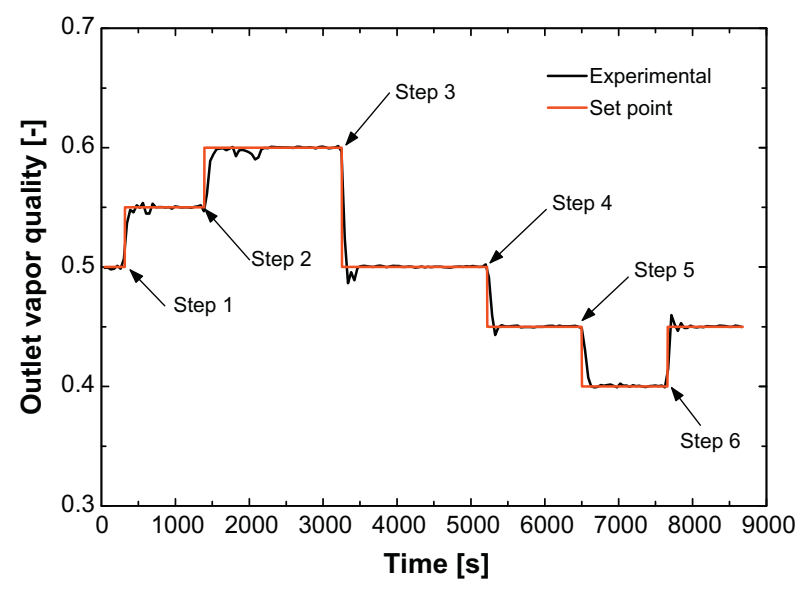

Fig. 24. Outlet vapor quality tracking test. (For interpretation of the references to colour in this figure legend, the reader is referred to the web version of this article.) 


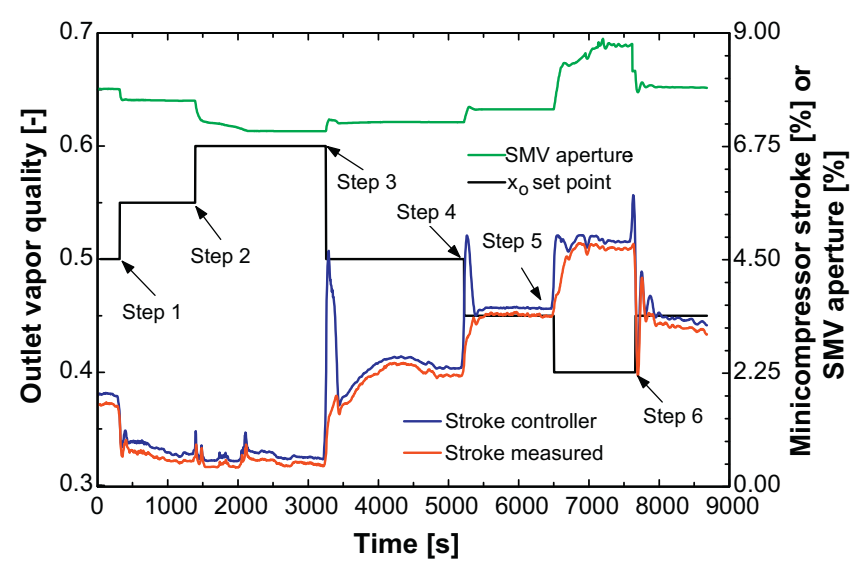

Fig. 25. SMV and minicompressor actuators. (For interpretation of the references to colour in this figure legend, the reader is referred to the web version of this article.)

Fig. 26 shows the effect of $x_{o}$ tracking tests on the LPS controller, where it can be observed that the coupling effect between the controlled variables $\Delta T_{c}$ and $x_{o}$ was negligible, since the controller was shown to be effective and efficient in maintaining the desired $\Delta T_{c}$ set point. The maximum overshoot observed for such a controller was $\pm 0.2^{\circ} \mathrm{C}$.

\subsubsection{SISO-SIMO controller}

The controllers designed previously, LPS controller (SISO strategy) and mini-compressor and SMV controllers (SIMO strategy), were integrated and evaluated through heat load disturbance rejection and flow distribution tests. The standard condition previously defined was used as a starting point. Fig. 27 shows the block diagram that represents such an integrated control strategy.

3.2.2.1. Heat load disturbance rejection. The heat load disturbance tests followed the same inputs considered for the previous system, i.e. periodic changing in the heat load on the MEs for a time period of $1.4 \mathrm{~s}$. The input heat loads changed between $75 \mathrm{~W}$ and $90 \mathrm{~W}$ on pseudo chip 1 and $75 \mathrm{~W}$ and $60 \mathrm{~W}$ on pseudo chip 2 . The set point of $x_{o}$ was considered to be 45\%. Figs. 28-30 show the results obtained for the average temperature of the pseudo chips, the variables under control $\left(\Delta T_{c}\right.$ and $\left.x_{o}\right)$ and the action of the controllers.

The maximum temperature variation observed was $1.5^{\circ} \mathrm{C}$, the same as for the previous system (viz. Figs. 17 and 28). Additionally, as can be seen in Fig. 29, the SIMO controller, i.e. the SMV and

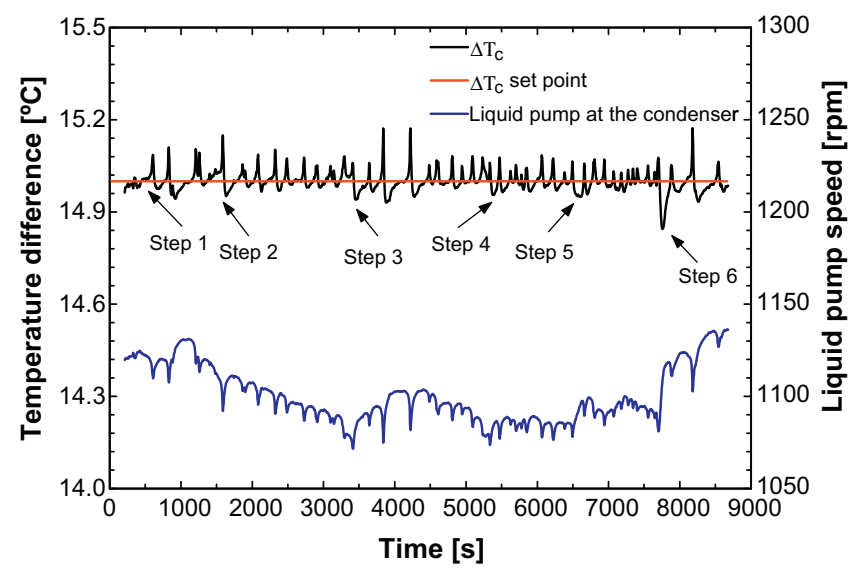

Fig. 26. Evaluation of coupling effect between $\Delta T_{c}$ and $x_{0}$. (For interpretation of the references to colour in this figure legend, the reader is referred to the web version of this article.) mini-compressor actuators controlling $x_{0}$, was effective in controlling $x_{0}$, showing a continuous process of searching associated with the periodic changing in the heat load. The maximum variation of $x_{o}$ regarding the set point was only $5 \%$. It was also observed that the SMV controller did not show any adverse effect on this test, with its aperture remaining constant.

The coupling effect between the parameters being controlled once again proved to be negligible, as can be seen in Fig. 30. To conclude, the integrated SISO-SIMO controller proved to be effective in the rejection disturbance of heat load, ensuring the stability of the system inside an acceptable level, i.e. the system control did not show instabilities or loss of control.

3.2.2.2. Flow distribution for non-uniform heat load. To evaluate the effect of unbalanced heat loads on the two pseudo chip temperatures and the controllability of the vapor compression cooling system, four different steps were given in the input powers to pseudo chips 1 and 2, which were changed between $40 \mathrm{~W}$ and $90 \mathrm{~W}$. The set point of $x_{o}$ and $\Delta T_{c}$ were fixed at $45 \%$ and $15{ }^{\circ} \mathrm{C}$, respectively. Figs. 31-34 show the input power changes, the average temperature of the pseudo chips and the action of the controllers to maintain the controllable parameters at their respective set points.

It can be observed from Figs. 31 and 32 that the difference of temperature between the chips increases when the difference in the applied input heat load increases. A higher heat load on one of the MEs generates a higher outlet vapor quality. To maintain the same pressure drop between the two MEs, which are in parallel flow, the mass flow rate needs to be reduced, with the consequence that there is an increase in temperature due to a decrease in the heat transfer coefficient. The highest difference observed was for step 3, where, after steady state has been reached, a difference of $12^{\circ} \mathrm{C}$ was observed. However, the limit of $85^{\circ} \mathrm{C}$ was still far away.

The SIMO controller, which uses the SMV and mini-compressor as actuators, proved to be effective and efficient in controlling $x_{0}$. The maximum overshoot observed in step 4 was only $0.07 \%$ in vapor quality (viz. Fig. 33). In this case, especially for steps 1 and 4, it can be seen that the SMV showed a more pronounced change in the aperture when compared with that obtained in the disturbance rejection tests. The SMV actuator can be seen as a fine adjustment of $x_{0}$. The anomalous operation to adjust/control the mini-compressor's stroke continued, i.e. the actual stroke is shorter than that requested by the controller.

Regarding the LPS controller, Fig. 34 shows that it was effective in maintaining the $15{ }^{\circ} \mathrm{C}$ set point, independent of changes in the heat loads on the MEs. The maximum overshoot remained between $\pm 0.5^{\circ} \mathrm{C}$ while no instabilities were observed.

Additionally and finally, the effect of the $\Delta T_{c}$ set point on the water temperature at the outlet of the condenser was investigated. The main interest in such an analysis is the exergy available in the condenser, which increases when the water temperature increases. Three set points were tested, i.e. $15^{\circ} \mathrm{C}, 10^{\circ} \mathrm{C}$ and $7.5^{\circ} \mathrm{C}$, and the results can be seen in Fig. 35. The heat load on the MEs was fixed at $75 \mathrm{~W}$, the $x_{o}$ set point at $50 \%$ and a steady state condition was considered for this analysis. As can be seen, an increase of about $14{ }^{\circ} \mathrm{C}$ was obtained in the outlet water

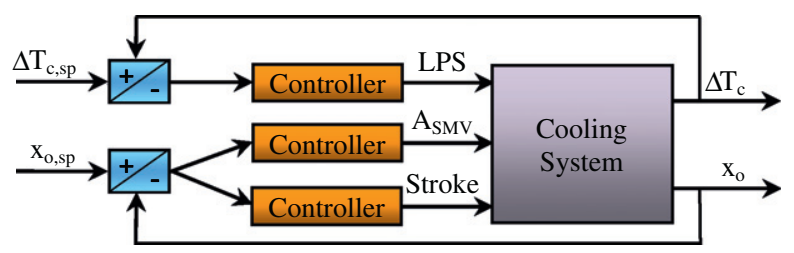

Fig. 27. The SISO-SIMO controller. 


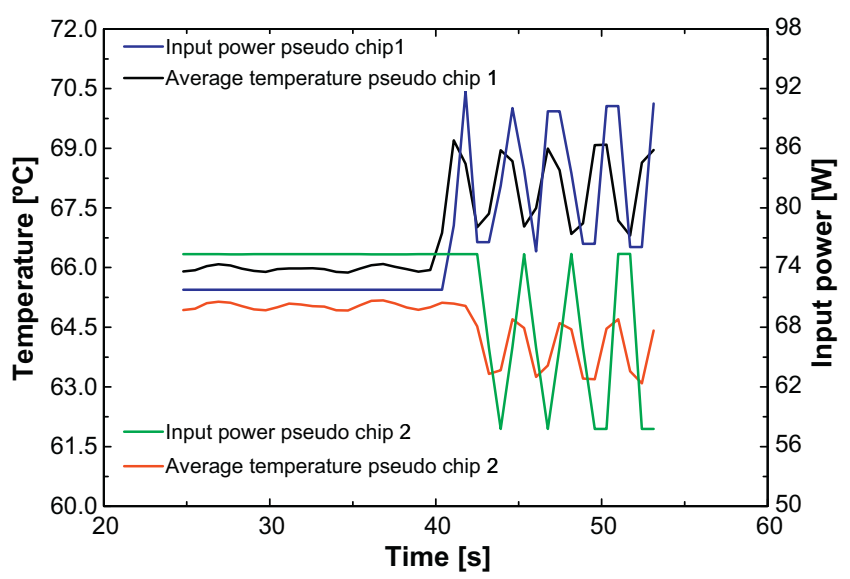

Fig. 28. Heat load disturbance and pseudo chips temperature. (For interpretation of the references to colour in this figure legend, the reader is referred to the web version of this article.)

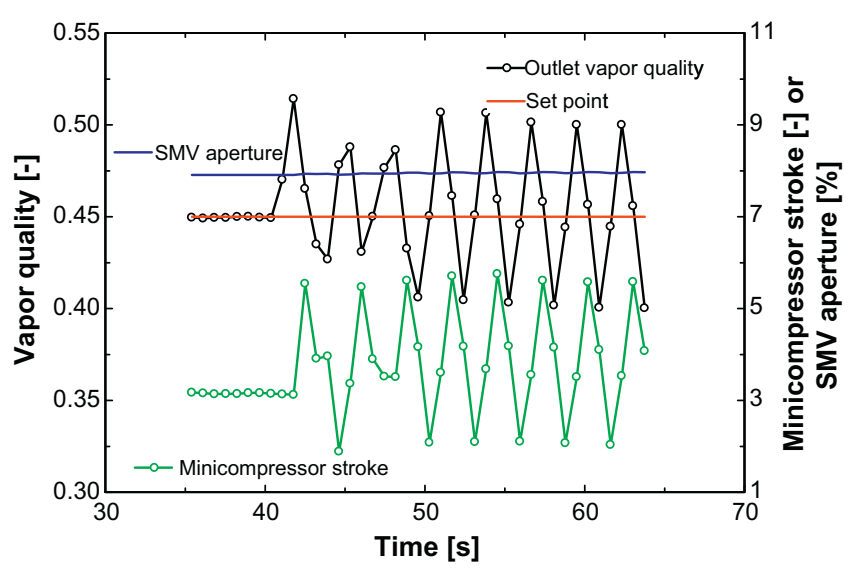

Fig. 29. Outlet vapor quality and SMV and minicompressor's controllers. (For interpretation of the references to colour in this figure legend, the reader is referred to the web version of this article.)

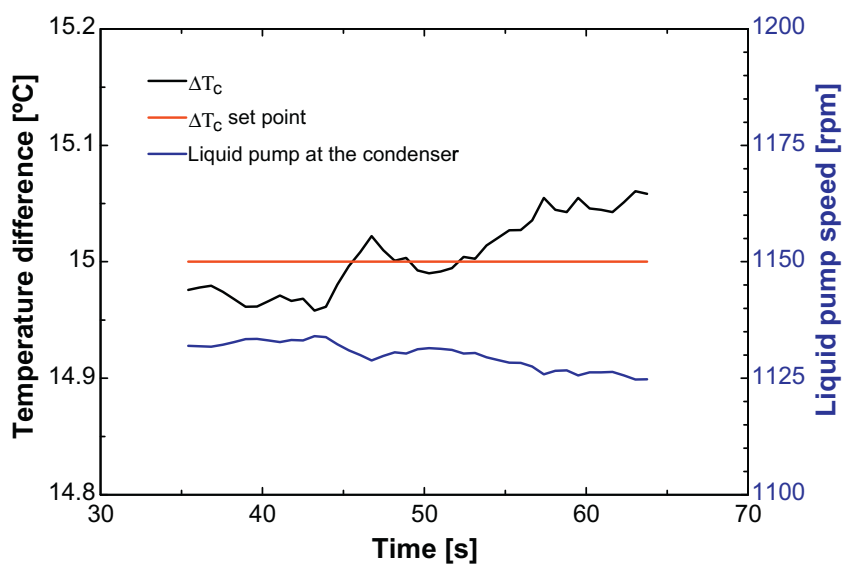

Fig. 30. $\Delta T_{c}$ and LPS controller. (For interpretation of the references to colour in this figure legend, the reader is referred to the web version of this article.)

temperature, which represents a much higher economic value for the energy recovered in the condenser. It also demonstrates the versatility of such a system in changing the set points without

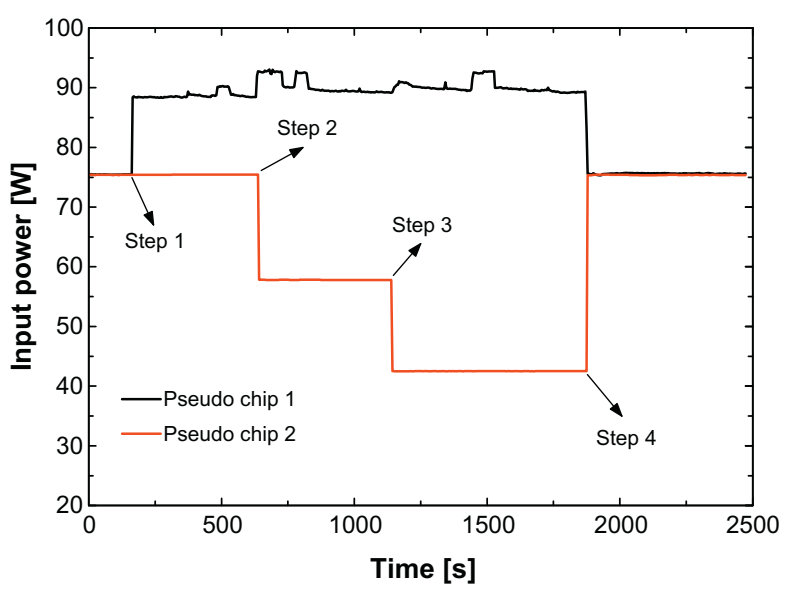

Fig. 31. Different heat loads on the MEs. (For interpretation of the references to colour in this figure legend, the reader is referred to the web version of this article.)

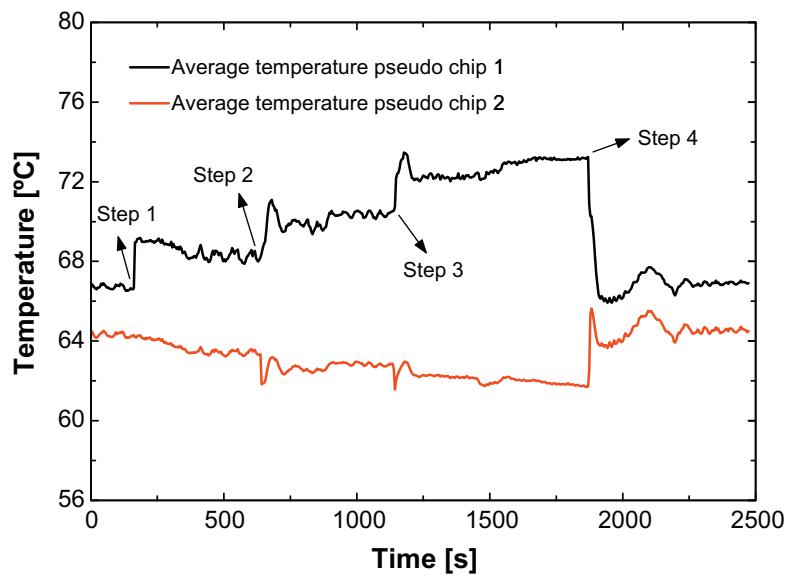

Fig. 32. Average temperatures on the two pseudo chips. (For interpretation of the references to colour in this figure legend, the reader is referred to the web version of this article.)

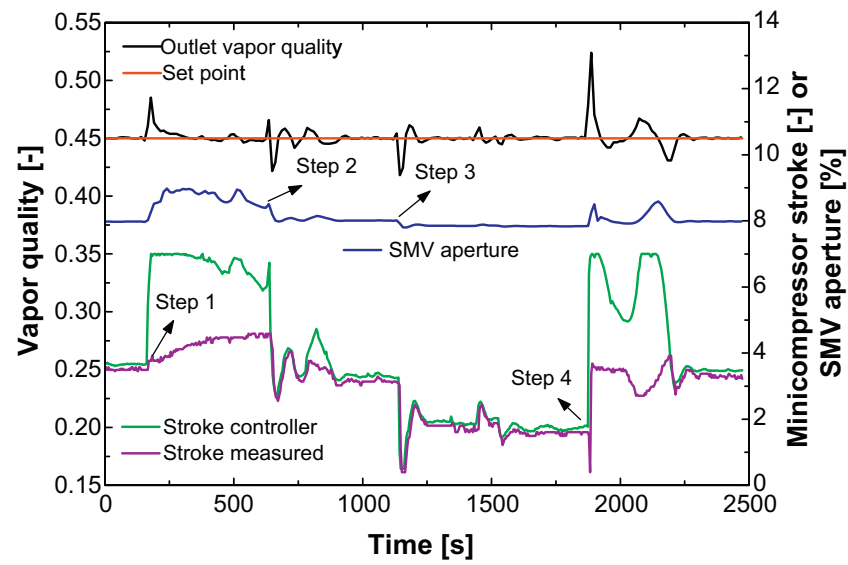

Fig. 33. Outlet vapor quality and SMV aperture. (For interpretation of the references to colour in this figure legend, the reader is referred to the web version of this article.)

compromising the cooling cycle performance and pseudo chip temperatures, which hardly varied when the $\Delta T_{c}$ set point was changed. 


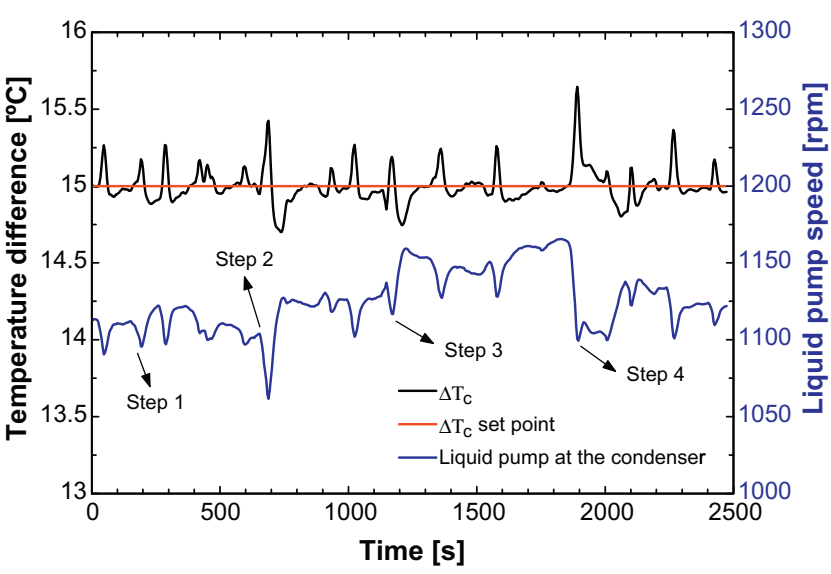

Fig. 34. $\Delta T_{c}$ and LPS controller. (For interpretation of the references to colour in this figure legend, the reader is referred to the web version of this article.)

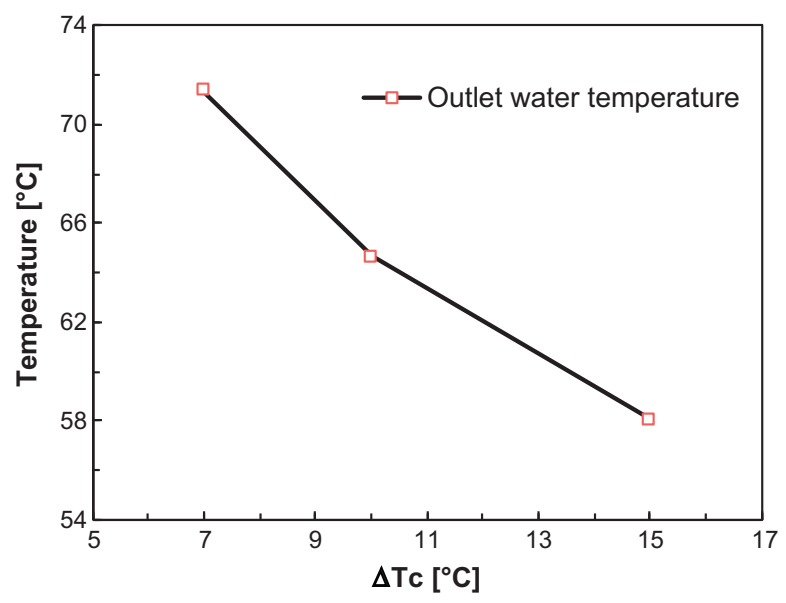

Fig. 35. Outlet water temperature vs. $\Delta T_{c}$ set point.

\section{Comparative analysis}

This section shows a comparative analysis between the two cooling systems evaluated, where a deeper investigation of exergy is made. To compare the performance of the liquid pumping and vapor compression cooling systems, which were experimentally evaluated and analyzed beforehand, a steady state condition was selected from the flow distribution tests. Such a comparison mainly evaluates the difference between the power consumption of the drivers and the available energy and exergy in the condenser. The experimental condition selected for the comparison was that the input powers on pseudo chips 1 and 2 were $90 \mathrm{~W}$ $\left(41.7 \mathrm{~W} / \mathrm{cm}^{2}\right)$ and $75 \mathrm{~W}\left(34.7 \mathrm{~W} / \mathrm{cm}^{2}\right)$, respectively.

\subsection{Power consumption}

Table 2 shows the results for the driver's power consumption and overall efficiency, the latter calculated as the ratio between the isentropic pumping or compression and the electrical input power. It also shows the two systems' input and output energies associated with components and piping and the thermodynamic conditions in the condenser for the main and secondary working fluids.
Table 2

Energy in and out in the systems and thermodynamic conditions in the condenser.

\begin{tabular}{lll}
\hline & LP cycle & VC cycle \\
\hline Energy in & & \\
Pump or compressor input power, W & 17.42 & 102.12 \\
Isentropic pumping or compression power, W & 0.048 & 27.77 \\
Driver overall efficiency, \% & 0.28 & 27.19 \\
Inverter power consumption, W & 10.0 & - \\
Electrical efficiency, \% & 42.58 & - \\
Mechanical power consumption, W & 7.42 & - \\
Mechanical efficiency, \% & 0.65 & - \\
Input power on the pseudo chips, W & 164.47 & 164.51 \\
Input power on the post heater, W & 0 & 125.63 \\
SMV input power, W & 0.49 & 0.95 \\
Energy out & & \\
Heat transfer in the condenser, W & 68.32 & 194.23 \\
Heat loss in the driver, W & 17.37 & 74.35 \\
Heat loss in the piping, W & 96.68 & 124.63 \\
Thermodynamic conditions in the condenser & & \\
Condensing temperature, ${ }^{\circ} \mathrm{C}$ & 59.96 & 80.48 \\
Inlet water temperature, ${ }^{\circ} \mathrm{C}$ & 39.96 & 14.61 \\
Outlet water temperature, ${ }^{\circ} \mathrm{C}$ & 49.32 & 65.04 \\
Mass flow rate of water, $\mathrm{kg} / \mathrm{h}$ & 6.28 & 3.31 \\
\hline
\end{tabular}

The results showed a higher driver's input power for the VC system, about 6 times higher, which naturally is associated with the energy expended to maintain the difference of pressure between the condenser and micro-evaporator. It is worth observing the drivers' low overall efficiency, which for the pump is mainly a consequence of leakage and slip of HFC134a in the gears. Such a characteristic is due to the low viscosity of the working fluid, being at the lower limit for the specified pump (hence a better pump would be advisable). As can be seen in Table 2, the mechanical efficiency is also very low, which confirms such an observation.

Regarding the mini-compressor, despite the high overall efficiency, it is actually considered to be low, especially when compared with conventional household compressors, which have values normally between 50\% and 70\% [25,26]. Such a low efficiency is potentially associated with the fact that the mini-compressor is operating at much higher suction/discharge pressures than its actual design conditions (domestic refrigerators).

It can also be seen that about $50 \%$ and $62 \%$ of the energy out of the VC and LP systems, respectively, are associated with heat losses. It shows that improvements can be made to improve the overall performance of the system, which would mainly be associated with the reduction of the driver and piping losses and, consequently, to increase the energy recovered in the condenser.

Finally the results showed a much higher temperature for the secondary fluid at the outlet of the condenser when using the VC system, which is related to the higher condensing temperature. This implies that a higher economic value is obtained for the energy available in the condenser. The analyses that follow will show the advantage of such a system when evaluating it from an exergy's point of view.

\subsection{Energy recovery}

To better explore and understand the difference between the two possibilities of cooling systems (vapor compression and liquid pumping) regarding energy recovery, i.e. exergy available in the condenser for a secondary application, the concept of exergy is introduced.

The steady state exergy rate balance is defined by Eq. (14) [27]. The first and second terms in the right side of the equality represent the exergy transfer accompanying heat and work, the third and fourth are the time rate of exergy transfer accompanying mass 
flow and flow work and, finally, the last term is the rate of exergy destroyed:

$0=\underbrace{\sum_{j}\left(1-\frac{T_{0}}{T_{i}}\right) \dot{Q}_{j}-\dot{W}_{c v}+\sum_{i} \dot{m}_{i} e_{f i}-\sum_{e} \dot{m}_{e} e_{f e}}_{\text {rate of exergy destruction }}-\underbrace{\dot{E}_{d}}_{\text {rate of exergy transfer }}$

It must be noted that an exergy reference environment should be defined. Such an environment represents the state of equilibrium or dead state. This equilibrium state defines the exergy as the maximum theoretical work obtainable when another system in a non-equilibrium state interacts with the environment to the equilibrium. For the present work the reference is defined as $295 \mathrm{~K}, 100 \mathrm{kPa}$ for water and $295 \mathrm{~K}, 603.28 \mathrm{kPa}$ and $50 \%$ of vapor quality for HFC134a.

The goal of the analysis is to determine, for each system, the exergy supplied, recovered and destroyed for a control volume enclosing the cooling system. With this, the overall exergetic efficiency, defined as the ratio between the recovered and supplied exergies, can be determined. The exergetic efficiency of each component is also evaluated. It qualitatively identifies and classifies the components that present higher irreversibilities, helping to decide which component to optimize to improve the thermodynamic performance of the cooling cycle. Table 2 from the previous section and Table 3 shows the results obtained regarding energy and exergy, respectively.

Firstly, the total exergy recovered is higher for the VC cooling system, which is a consequence of the higher exergy supplied by the driver and the exergy of the post heater, where the latter was not being considered in the LP system's experimental tests. However, it is highlighted that this high exergy is the subject of interest of the owner of a secondary application of the recovered heat.

Regarding the exergetic efficiency of the components considered in the cooling systems, the driver followed by the condenser showed the lowest values, which implies that to improve the thermodynamic performance of the cooling systems such a components must be optimized in the design. Special attention must also be given to the exergy destroyed in the piping, which repre-

Table 3

Exergetic analysis for the VC and LP cooling systems.

\begin{tabular}{lll}
\hline & LP cycle & VC cycle \\
\hline Exergy supplied, W & 40.1 & 146.7 \\
Exergy destroyed or irreversibility, $W$ & & \\
Pump or compressor & 17.4 & 74.4 \\
Condenser & 3.5 & 21.4 \\
ME1 & 3.4 & 3.6 \\
ME2 & 0.9 & 0.8 \\
Post heater & - & 9.0 \\
iHEx & - & 1.3 \\
LPR & - & 0.9 \\
SMV & 0.27 & 3.3 \\
Piping & 9.7 & 21.3 \\
Total & 35.2 & 136.0 \\
Exergy recovered, W & $\mathbf{4 . 9}$ & $\mathbf{1 0 . 7}$ \\
Exergetic efficiency, \% & & \\
Pump or compressor & 0.03 & 27.2 \\
Condenser & 58.4 & 33.6 \\
ME1 & 72.6 & 70.7 \\
ME2 & 90.7 & 91.1 \\
Post heater & - & 59.3 \\
iHEx & - & 78.8 \\
LPR & - & 72.7 \\
SMV & - & - \\
Piping & - & - \\
Overall & $\mathbf{1 2 . 3}$ & $\mathbf{7 . 3}$ \\
\hline & &
\end{tabular}

sents about $28 \%$ and $16 \%$ of the overall exergy destroyed in the LP and VC systems, the latter being the same order of magnitude as that in the condenser. This implies that a better insulation of the test unit is required to minimize the heat losses, i.e. exergy lost or destroyed.

It can also be observed that the overall exergetic efficiency was lower for the VC cooling system, with the compressor, condenser and piping being the main culprits. The overall exergetic efficiency also shows that there is a huge need to improve the thermodynamic performance of the cooling systems, since only an average of $10 \%$ of the supplied exergy is recovered.

The results and analyses above may lead one to conclude that the LP system is better in terms of exergy and energy. However, such a conclusion is not fair, especially when looking for the potential to improve the components' exergetic efficiency and to reduce the piping's exergy destroyed. It seems both systems can be optimized, i.e. better designed so that improvements will be generated, since the present setups were the first of a kind. It is also important to mention that the results shown here represent only the initial step in a much larger experimental campaign and this more extensive experimental campaign will be used to generalize the results.

To consider the effect of an improvement in the drivers' overall efficiency (the worst component in terms of exergetic efficiency) on the overall exergetic efficiency of the systems, a thermodynamic simulation was developed considering as inputs the experimental results used in the previous analysis. Fig. 36 shows the results, where can be seen that the effect on the exergetic efficiency is much higher when using a VC as a driver and that there is a point where the exergetic efficiency of the VC system surpasses that of the LP system (at about 65\%). From an exergetic point of view, only after this point does the VC cooling system become competitive with the LP cooling system. It is also important to remember that the other exergy losses must be considered and the matching point of exergetic efficiency showed in Fig. 36 can be changed to higher or lower values in that case.

Finally, it is important remembering that the thermodynamic performance alone (energy balance) does not permit implementing the analysis shown beforehand. Exergy analysis clearly identifies efficiency improvements and reductions in thermodynamic losses attributable to green technologies. Additional advantages of such analyses are the potential to evaluate green technology aspects such as environmental impact or sustainable development (normally associated with carbon dioxide emissions) and economics ("exergy, not energy, is the commodity of value in a system, and assign costs and/or prices to exergy-related variables" [28]).

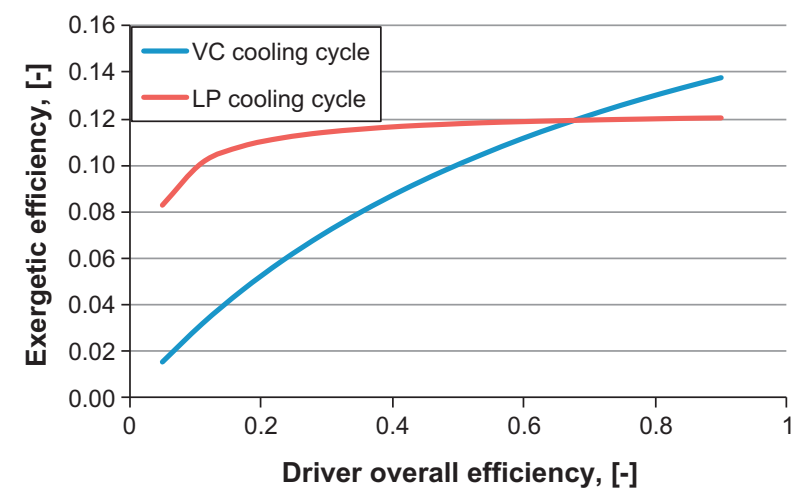

Fig. 36. Exergetic efficiency vs. driver overall efficiency. (For interpretation of the references to colour in this figure legend, the reader is referred to the web version of this article.) 


\section{Conclusions}

Two specific on-chip two-phase cooling cycles described by [16] were built in the LTCM lab and experimentally tested and evaluated. The cycles were differentiated by their drivers, i.e. the first was driven by a liquid pump and the second by a mini-compressor. Aspects such as energy consumption, exergetic efficiency and controllability were investigated. The controllers designed were evaluated by tracking and disturbance rejection tests, which were shown to be efficient and effective. The average temperatures of the pseudo chips were maintained below the limit of $85^{\circ} \mathrm{C}$ for all tests evaluated in steady state and transient conditions.

In general, simple SISO strategies were sufficient to attain the requirements of control, i.e. more complex MIMO strategies were not necessary for this application. Regarding energy and exergy analyses, the experimental results showed that both systems can be thermodynamically improved since only about $10 \%$ of the exergy supplied is in fact recovered in the condenser in the present setup. Additional analysis highlighted the effect of the $\Delta T_{c}$ set point on the water temperature (secondary fluid) at the outlet of condenser. The results showed that water temperatures higher than $70^{\circ} \mathrm{C}$ can be obtained when the $\Delta T_{c}$ set point is reduced from $15^{\circ} \mathrm{C}$ to $7{ }^{\circ} \mathrm{C}$ without compromising the cooling system performance and pseudo chip temperatures, which is interesting when the subject of energy recovery is considered. Finally, the results presented were not generalized since only a limited number of tests were done and a more detailed experimental campaign is necessary to better describe and compare both systems presented.

\section{Acknowledgements}

The Swiss Commission for Technology and Innovation (CTI) contract number 6862.2 DCS-NM entitled "Micro-Evaporation Cooling System for High Performance Micro-Processors: Development of Prototype Units and Performance Testing" directed by the LTCM laboratory sponsored this work along with the project's industrial partners: IBM Zürich Research Laboratory (Switzerland) and Embraco (Brazil). J.B. Marcinichen wishes to thank CAPES ("Coordenação de Aperfeiçoamento de Pessoal de Nível Superior") for a one year fellowship to work at the LTCM laboratory.

\section{References}

[1] EPA. Report to congress on server and data center energy efficiency public law, US Environmental Protection Agency; 2007. p. 109-431.

[2] Larson JB. America's Energy Security Trust Fund Act of 2009, in H.R. 1337; 2009.

[3] Koomey JG. Estimating regional power consumption by servers: a technical note. Lawrence Berkeley National Laboratory: Oakland, CA; 2007.

[4] Hannemann R, Marsala J, Pitasi M. Pumped liquid multiphase cooling. In: IMECE - international mechanical engineering congress and exposition. Anaheim, CA, USA, paper 60669; 2004.

[5] Mongia R, Masahiro K, DiStefano E, Barry J, Chen W, Izenson M, et al. Small scale refrigeration system for electronics cooling within a notebook computer. In: ITHERM 2006. San Diego, CA; 2006.
[6] Trutassanawin S, Groll EA, Garimella SV, Cremaschi L. Experimental investigation of a miniature-scale refrigeration system for electronics cooling. IEEE Trans Compon Pack Technol 2006;29(3):678-87.

[7] Zhang T, Wen JT, Peles Y, Catano J, Zhou R, Jensen MK. Two-phase refrigerant flow instability analysis and active control in transient electronics cooling systems. Int J Multiphase Flow 2011;37:84-97.

[8] Zhou R, Zhou R, Catano J, Wen JT, Michna GJ, Peles Y, et al. The steady-state modeling and optimization of a refrigeration system for high heat flux removal. Appl Therm Eng 2010;2:1. doi:10.1016/j.applithermaleng.2010. $\underline{05.023}$.

[9] Heydari A. Miniature vapor compression refrigeration systems for active cooling of high performance computers. In: Inter society conference on thermal phenomena; 2002.

[10] Marcinichen JB, Thome JR. Refrigerated cooling of microprocessors with microevaporation new novel two-phase cooling cycles: a green steady-state simulation code. In: 13th Brazilian congress of thermal sciences and engineering - Encit 2010. Uberlândia, MG, Brazil; 2010.

[11] Marcinichen JB, Thome JR. New novel green computer two-phase cooling cycle: a model for its steady-state simulation. In: 23rd international conference on efficiency, cost, optimization, simulation and environmental impact of energy systems - ECOS2010. Lausanne, Switzerland; 2010.

[12] Ganapati P. Water-cooled supercomputer doubles as dorm space heater; 2009 <http://www.wired.com/gadgetlab/2009/06/ibm-supercomputer/>.

[13] Meijer GI, Brunschwiler T, Michel B. Using waste heat from datacenters to minimize carbon dioxide emissions. In: ERCIM News; 2009. p. 23-4.

[14] Brunschwiler T, Meijer GI, Paredes S, Escher W, Michel B. Direct wast heat utilization from liquid-cooled supercomputers. In: 14th Int heat transfer conference. August 8-13, Washington, DC, USA; 2010.

[15] Olivier JA, Marcinichen JB, Thome JR. Two-phase cooling of datacenters: reduction in energy costs and improved efficiencies. In: 13th Brazilian congress of thermal sciences and engineering - ENCIT2010. Uberlandia, MG, Brazil; 2010.

[16] Marcinichen JB, Thome JR, Michel B. Cooling of microprocessors with microevaporation: a novel two-phase cooling cycle. Int J Refrig 2010.

[17] Costa-Patry E, Olivier JA, Michel B, Thome JR. Two-phase flow of refrigerants in $85 \mu \mathrm{m}$-wide multi-microchannels - Part II. Heat transfer with 35 local heaters. Int J Heat Fluid Flow 2011;32(2):464-76

[18] Costa-Patry E, Olivier JA, Nichita BA, Michel B, Thome JR. Two-phase flow of refrigerants in $85 \mu \mathrm{m}$-wide multi-microchannels: Part I - Pressure drop. Int J Heat Fluid Flow 2011;32(2):451-63.

[19] Costa-Patry E, Olivier JA, Thome JR. Hot-spot effects on two-phase flow of R245fa in $85 \mu \mathrm{m}$-wide multi-microchannels. In: 16th international workshop on thermal investigations of IC's and systems. Barcelona, Spain; 2010.

[20] Kline SJ, McClintock FA. Describing uncertainties in single-sample experiments. Mech Eng 1953;75:3-8.

[21] Lemmon EW, Huber ML, McLinden MO. Refprop8, Standard Reference Database 23. In: National Institute of Standards and Technology. Gaithersburg, MD, USA; 2007.

[22] Karimi A, Kunze M, Longchamp R. Robust controller design by linear programming with application to a double-axis positioning system. Control Eng Practice 2007;15(2):197-208.

[23] Olivier JA, Thome JR. Two-phase cooling of electronics with multimicrochannel evaporators. In: NATO: AVT-178 specialists' meeting on system level thermal management for enhanced platform efficiency. Bucarest, Romania; 2010.

[24] Kunze M, Karimi A, Longchamp R. Gain-scheduling controller design by linear programming. In: European Control Conference. Kos, Greece; 2007.

[25] Hermes CJL, Melo C, Knabben FT, Gonçalves JM. Prediction of the energy consumption of household refrigerators and freezers via steady-state simulation. Int J Appl Energy 2009;86:1311-9.

[26] Gonçalves JM, Melo C, Hermes CJL, Barbosa JR. Experimental mapping of the thermodynamic losses in vapor compression refrigeration systems. J Brazilian Soc Mech Sci Eng 2011;33(2):159-65.

[27] Moran MJ, Howard I, Shapiro N, editors. Fundamentals of engineering thermodynamics, 6th ed. John Wiley \& Sons; 2010. 725p.

[28] Rosen MA, Dincer I, Kanoglu M. Role of exergy in increasing efficiency and sustainability and reducing environmental impact. Energy Policy 2008;36:128-37. 